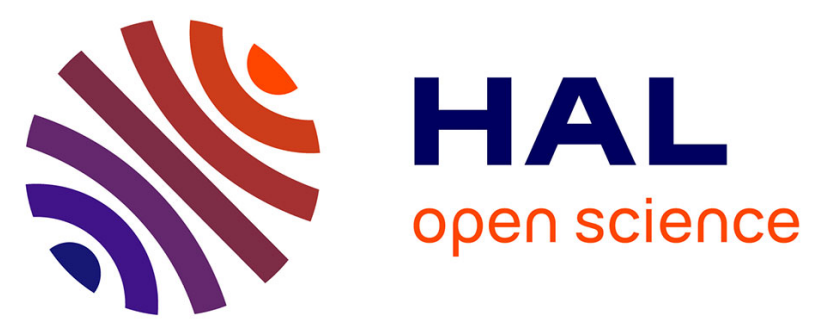

\title{
Update of French society for rheumatology recommendations for managing rheumatoid arthritis
}

Claire Daien, Charlotte Hua, Cécile Gaujoux-Viala, Alain Cantagrel,

Madeleine Dubremetz, Maxime Dougados, Bruno Fautrel, Xavier Mariette, Nathalie Nayral, Christophe Richez, et al.

\section{To cite this version:}

Claire Daien, Charlotte Hua, Cécile Gaujoux-Viala, Alain Cantagrel, Madeleine Dubremetz, et al.. Update of French society for rheumatology recommendations for managing rheumatoid arthritis. Joint Bone Spine, 2019, 86 (2), pp.135-150. 10.1016/j.jbspin.2018.10.002 . hal-02264783

\section{HAL Id: hal-02264783 \\ https://hal.univ-brest.fr/hal-02264783}

Submitted on 22 Oct 2021

HAL is a multi-disciplinary open access archive for the deposit and dissemination of scientific research documents, whether they are published or not. The documents may come from teaching and research institutions in France or abroad, or from public or private research centers.
L'archive ouverte pluridisciplinaire HAL, est destinée au dépôt et à la diffusion de documents scientifiques de niveau recherche, publiés ou non, émanant des établissements d'enseignement et de recherche français ou étrangers, des laboratoires publics ou privés.

\section{(ㅇ)(1) $\$$}

Distributed under a Creative Commons Attribution - NonCommerciall 4.0 International 


\section{Update of French Society for Rheumatology Recommendations for Managing Rheumatoid Arthritis}

Claire Daien $^{\mathrm{a}, \mathrm{b} *}$, Charlotte Hua ${ }^{\mathrm{c}, \mathrm{d} *}$, Cécile Gaujoux-Viala ${ }^{\mathrm{c}, \mathrm{d}}$, Alain Cantagrel ${ }^{\mathrm{e}, \mathrm{f},}$ Madeleine Dubremetz $^{\mathrm{g}}$, Maxime Dougados ${ }^{\mathrm{h}, \mathrm{i}, \mathrm{j}}$, Bruno Fautrel $^{\mathrm{k}, \mathrm{l}}$, Xavier Mariette $^{\mathrm{m}, \mathrm{n},}$ Nathalie Nayral ${ }^{\mathrm{a}, \mathrm{b}}$,

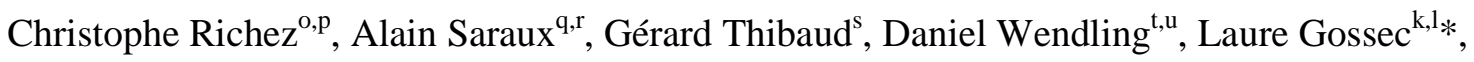
Bernard Combe $e^{\mathrm{a}, \mathrm{b} *}$

${ }^{\mathrm{a}}$ Service de Rhumatologie, CHU de Montpellier, 34295 Montpellier, France

${ }^{\mathrm{b}}$ Université de Montpellier, 34295 Montpellier, France

${ }^{c, d}$ Service de Rhumatologie, CHU de Nîmes, 30029 Nîmes, France

EA2415, Université de Montpellier, 30029 Nîmes, France

${ }^{\text {e }}$ Service de Rhumatologie, CHU de Toulouse, 31059 Toulouse, France

${ }^{\mathrm{f}}$ Université Toulouse III, UMR Inserm 1043-CNRS 5282, 31059 Toulouse, France

${ }^{\mathrm{g}}$ Association française des Polyarthritiques et des Rhumatismes Inflammatoires Chroniques

(AFP RIC), 75011 Paris, France

${ }^{\mathrm{h}}$ Paris Descartes University, 75006 Paris, France

${ }^{\mathrm{i}}$ Department of Rheumatology - Hôpital Cochin. Assistance Publique - Hôpitaux de Paris, 75006 Paris, France

${ }^{\mathrm{j}}$ INSERM (U1153), Clinical epidemiology and biostatistics, PRES Sorbonne Paris-Cité.

75006 Paris, France

${ }^{\mathrm{k}}$ Sorbonne Université, 75013 Paris France

${ }^{1}$ Pitié Salpêtrière hospital, APHP, Rheumatology department, 75013 Paris, France

${ }^{\mathrm{m}}$ Service de Rhumatologie, Hôpitaux Universitaires Paris-Sud, AP-HP, 94270 Le KremlinBicêtre, France 
${ }^{\mathrm{n}}$ Université Paris-Sud, INSERM UMR1184, 94270 Le Kremlin-Bicêtre, France

${ }^{\circ}$ Service de Rhumatologie, CHU de Bordeaux, 33000 Bordeaux, France

${ }^{\mathrm{p}}$ Université de Bordeaux, 33000 Bordeaux, France

${ }^{\mathrm{q}}$ Service de Rhumatologie, CHU de Brest, 29200 Brest, France

${ }^{\mathrm{r}}$ INSERM 1227, Université de Bretagne occidentale, 29200 Brest, France

sAssociation Nationale de Défense contre 1'Arthrite Rhumatoïde (ANDAR), 75014 Paris,

France

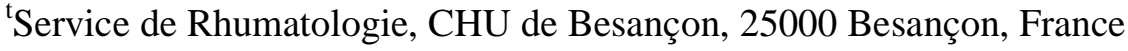

uUniversité de Franche-Comté, 25000 Besançon, France

Corresponding author: Dr Claire Daien, Département de Rhumatologie, Hôpital

Lapeyronie, 371 av du Doyen Giraud, 34295 Montpellier, France

c-daien@ chu-montpellier.fr

* $\mathrm{CD}$ and $\mathrm{CH}$ contributed equally to this work and should be considered co-first authors. LG and $\mathrm{BC}$ contributed equally to this work and should be considered co-last authors. 


\section{ABSTRACT}

The 2014 French Society for Rheumatology (Société Française de Rheumatologie, SFR) recommendations about the management of rheumatoid arthritis (RA) have been updated by a task force composed of 12 expert rheumatologists, 2 patient self-help group representatives, and an occupational therapist. The material used by the task force included recent EULAR recommendations, a systematic literature review, and expert opinion. Four general principles and 15 recommendations were developed. The general principles emphasize the need for shared decision-making between the rheumatologist and the patient and for a global management program including both pharmacological and nonpharmacological treatments. The recommendations deal with the diagnostic strategy for RA, treatment targets, management organization, drug selection based on the treatment line and prognostic factors, management of remissions, and global patient management. Diseasemodifying antirheumatic drug (DMARD) therapy should be started as early as possible. Validated composite scores should be determined at regular intervals to assess disease activity -- according to the tight disease control concept -- to achieve the treatment target, i.e., a remission. Methotrexate is the recommended first-line DMARD. The treatment should be optimized when methotrexate is poorly tolerated or inadequately effective. While waiting for conventional synthetic DMARDs to take effect, glucocorticoid therapy can be used, for a brief period to keep the cumulative dose low. When a sustained remission without structural progression is achieved in a patient who is not taking glucocorticoid therapy, targeted therapy de-escalation according to tight disease control principles should be considered. Patients should be periodically screened for comorbidities and their risk factors, which should be evaluated and treated.

Keywords: Rheumatoid arthritis. Diagnosis. Treatment. Targeted treatment. DMARD. Recommendations. 


\section{Introduction}

Since 2014 when the latest recommendations about the management of rheumatoid arthritis (RA) were issued by the French Society for Rheumatology (Société Française de Rheumatologie, SFR) [1], new data have been published. Thus, new information is available on pharmacological treatments (including newly marketed drugs and therapeutic strategies, notably for patients in remission), nonpharmacological treatments (rehabilitation and therapeutic patient education [TPE]), and comorbidities. Recommendations must be updated regularly based on the current literature to ensure that they provide optimal guidance to all those involved in managing RA, thereby further improving the quality of life, functional outcomes, and survival of patients with RA. The European League Against Rheumatism (EULAR) has also conformed to this necessity, issuing updated recommendations about RA and early arthritis in 2016 [2,3].

French recommendations about RA aim to deal with all the dimensions of RA management including the diagnosis, treatment, follow-up, management of remissions, and management of comorbidities. Although primarily intended for rheumatologists, they may be useful also to other physicians who provide care to patients with RA such as primary-care physicians, as well as to other healthcare professionals, medical students, patient self-help organizations, and health authorities.

Thus, the objective of this work was to update SFR recommendations on managing RA in order to provide patients with optimal management. 


\section{Methods}

The SFR convened a task force of 12 hospital- or community-based rheumatologists, 2 patients with RA who were members of patient self-help organizations, and an occupational therapist. The task force members' places of work were distributed throughout France. The material used by the task force included the 2014 SFR and 2016 EULAR recommendations for the management of RA and early arthritis [1-3]. In addition, a systematic literature review was conducted by 2 task force members $(\mathrm{CD}$ and $\mathrm{CH})$ to retrieve data published between completion of the literature review for the earlier recommendations (i.e., between November 2015 and February 2016 depending on the item) and October 2017 [4-8]. The systematic literature review involved searches of MedLine (via PubMed) and a review of abstracts published at the 2016 and 2017 meetings held by the EULAR and American College of Rheumatology (ACR). The objective of the literature review was to identify recently published data of use for answering 11 questions previously identified by the task force. These questions referred to the time to RA treatment initiation, with the window of opportunity concept; diagnosis, prognosis, and treatment of RA, as well as treatment strategies; management of remissions; and global patient management including the management of comorbidities. In January 2018, the task force drafted the update to the SFR recommendations, which was then finalized via several email rounds. The recommendations were then reviewed by a panel of 40 experts including hospital- and community-based rheumatologists, other healthcare professionals, and patients designated by patient self-help organizations. Each panel member scored each recommendation on a $0-10$ scale where 0 indicated complete disagreement and 10 complete agreement. The wording of some of the recommendations was modified according to the comments made by the panel. The level of the underlying evidence and the grade of each recommendation were determined [9]. 


\section{Results}

Table 1 defines the main terms used and Figure 1 clarifies the nomenclature of diseasemodifying antirheumatic drugs (DMARDs). Table 2 lists the 4 general principles and 15 recommendations and shows the levels of evidence and grades of the recommendations, as well as the level of agreement of the task force and review panel with each recommendation.

\subsection{General principles}

Principle A: The optimal management of patients with RA requires a dialogue between the rheumatologist and patient to ensure that the patient receives the information and education needed to share in his or her management decisions.

This principle was the same in 2014. As with all chronic diseases, patients with RA must be actively involved in their own management. Shared decision-making, which is the bedrock of the therapeutic partnership, requires all patients to have access to informational and educational resources that provide them with substantial knowledge about their disease and its management, so that they can make informed decisions in tandem with their rheumatologist $[1,10,11]$. During a dedicated visit, the rheumatologist should disclose the diagnosis of RA then establish a treatment strategy in partnership with the patient. TPE promotes self-sufficiency and self-efficacy and allows the patient to become a competent partner in the management process. Therefore, TPE must extend beyond providing education about pharmacological treatments. The French National Health Authority (Haute Autorité de Santé, HAS) recommends providing TPE shortly after disclosure of the diagnosis or at any other time if TPE was not offered previously or was declined by the patient [12]. EULAR recommendations state that all patients with chronic inflammatory joint disease should have access to TPE during the course of their illness, including, at the minimum, at the time of the diagnosis (disclosure phase), whenever the medication regimen is changed (priming phase), 
and whenever physical or psychological issues make TPE desirable [11]. The HAS

recommends developing a TPE protocol that progresses through the following four stages:

educational diagnosis, personalized TPE program (with hierarchization of the treatment targets), delivery of individual or group TPE sessions, and assessment of acquired

competencies [12]. The EULAR provides a broader definition of the TPE modalities that can be offered to patients [11]. Given the disparities in TPE availability across France, SFR experts felt that TPE should be considered for all patients but that its modalities may vary according to local resources.

\section{Principle B: The rheumatologist is the specialist who should be in charge of managing} patients with RA. The primary-care physician plays a crucial role in detecting RA and in providing follow-up in conjunction with the rheumatologist.

This principle also is the same as in 2014. Recent EULAR recommendations also state that RA patients should be managed by rheumatologists [2,3]. One source of support for this principle consists in published evidence that rheumatologists diagnose and treat RA earlier than do other physicians, thereby benefiting the functional and structural prognosis of the patients [4]. Nonetheless, the primary-care physician is in a unique position to ensure the early detection of possible RA then to promptly refer the patient to a rheumatologist [13]. Primary-care physicians also play a major role in providing follow-up, monitoring treatments, and managing comorbidities. They may also be involved, in partnership with the rheumatologist, in renewing and adjusting the medications. Thus, the rheumatologist and primary-care physician are both key components of the care pathway traveled by patients with RA and should work together to build a personalized and coordinated management framework. 
Principle C: Patients with RA should be offered a global management program including drug treatments, therapeutic patient education and, as appropriate, comorbidity management, psychological support, assistance with social and occupational issues, functional rehabilitation, and/or surgery.

This new principle is recommendation 15 in the 2014 recommendations. The task force determined that this generic statement was a general principle rather than a recommendation, since a global management program including pharmacological and nonpharmacological treatments should be offered and tailored to every patient with RA. Nonpharmacological interventions include TPE (see Principle A); comorbidity management (see recommendation 15); psychological, social, and educational support; nonpharmacological treatments for chronic pain; rehabilitation therapy; and surgery [14]. Although published data are limited. the experts considered that physical treatments such as physiotherapy, occupational therapy, and podiatric care benefit patients with RA, notably in terms of functional capabilities [3,5]. Appropriate orthoses and assistive devices can be helpful to some patients. Despite the scarcity of data on the efficacy of psychological support, the experts considered that psychological support should be offered in some cases. Their opinion was similar regarding social and occupational support. Finally, all patients with RA should be informed of the existence of patient self-help organizations, notably upon disclosure of the diagnosis, and given contact information if they express interest. Depending on patient expectations, this global management program can be instituted gradually instead of being implemented in its entirety as soon as the diagnosis is made.

Principe D: The cost of RA and of its consequences and treatments, for both the individual and society, should be considered when making treatment decisions. 
This principle is a very slight modification of previous Principle C in the 2014 recommendations: the word "high" used to qualify costs has been removed. Taking the costs of RA management into account is also among the general principles accompanying the 2016 EULAR recommendations [2]. Although treatment decisions should be based primarily on efficacy and safety data, they should also factor in the overall cost of the therapeutic management of RA. The introduction of targeted treatments has increased the direct costs of RA management. However, RA itself generates both direct costs (admissions, surgical procedures) and indirect costs (related to loss of productivity, sick leaves, and work incapacitation) [15]. Given their high efficacy, targeted treatments can decrease these direct and indirect costs [16-18]. In addition, current strategies involving targeted therapy deescalation, combined with the introduction of biosimilars, are diminishing the individual costs of DMARD therapy $[19,20]$. The latest EULAR recommendations state that, among treatment strategies of similar efficacy and safety, the least costly should be used [2].

\subsection{Recommendations}

\subsubsection{Diagnosis}

\section{Recommendation 1: A diagnosis of RA should be considered in patients with specific clinical findings such as joint swelling (clinical arthritis), morning stiffness lasting longer than 30 minutes, and a positive hand or forefoot squeeze test then confirmed as promptly as possible (ideally within 6 weeks) by a physical examination performed by a rheumatologist, laboratory tests (erythrocyte sedimentation rate [ESR], C-reactive protein [CRP], anti- citrullinated protein antibodies [ACPA], and rheumatoid factors [RFs]), and imaging studies (radiographs with or without ultrasonography), after ruling out the differential diagnoses.}

The first part of this recommendations is unchanged compared to 2014. Joint swelling (synovitis), particularly involving several joints, and notably located at the hands, suggests 
RA. Morning stiffness for longer than 30 minutes and a positive squeeze test (pain elicited by side-to-side pressure across the metacarpophalangeal [MCP] and/or metatarsophalangeal $[\mathrm{MTP}]$ joints) further strengthen the suspicion of RA. A recent EULAR publication identifies several parameters that should suggest inflammatory joint disease in patients with arthralgia, including symptom onset within the past year, MCP joint involvement, morning stiffness for longer than 1 hour, greater symptom severity in the morning, history of RA in a first-degree relative, difficulty making a fist, and positive MCP squeeze test [21].

The second part of the recommendations is slightly amended compared to 2014 to highlight the major contribution of the physical examination to the diagnosis of RA and the need for establishing the diagnosis very soon after symptom onset. Published evidence indicates that patients referred rapidly to a rheumatologist after symptom onset have better structural outcomes and require fewer orthopedic procedures compared to patients referred later on [4]. Given these data and their own experience, the task force experts recommended that the diagnosis of RA be confirmed within 6 weeks after symptom onset. Compared to the 2014 recommendations, the task force also considered that the key role for the physical examination in RA screening needed to be emphasized. Primary-care physicians should be trained in recognizing signs suggestive of early inflammatory joint disease, and rheumatologists must be available to assess referred patients rapidly [22]. Ultrasonography, as a noninvasive, inexpensive, and widely available imaging technique, may provide diagnostic assistance in some cases, by detecting synovitis when the physical examination is difficult (due to obesity of MTP involvement for instance) or by helping to determine the number of involved joints $[23,24]$. Nevertheless, based on published evidence, and although ultrasonography has shown good sensitivity for detecting arthritis and identifying patients at risk for RA, the task force considered that ultrasonography does not deserve to be performed routinely, given its low specificity $[3,4,25,26]$. Evidence that ultrasonography exhibits good 
specificity but limited sensitivity for identifying bone erosions in patients with arthritis was felt to also militate against routine ultrasonography for the diagnosis of RA [25]. Finally, recent evidence combined with cost considerations seem to indicate only limited clinical relevance of magnetic resonance imaging as a diagnostic test for RA [3,4].

Among imaging studies, standard anteroposterior radiographs of the hands and anteroposterior and oblique radiographs of the feet are again considered in these recommendations as first-line investigations for assisting in the diagnosis of RA, as they may show erosions typical for the disease. The EULAR definition of typical RA erosive disease consists in erosions involving three or more separate joints at any of the following sites: MCP joints, proximal interphalangeal joints, wrist, and MTP joints [27].

In patients without typical erosive disease, confirmation of a diagnosis of RA relies on a set of converging clinical and laboratory findings, which also eliminate differential diagnoses. No consensus exists regarding the laboratory tests to be obtained in patients with early arthritis. The task force suggests performing the laboratory tests recommended by the HAS in 2007, the SFR in 2014, and EULAR in 2016. Thus, the minimum battery of tests should include a CRP assay; erythrocyte sedimentation rate measurement if possible; a full blood cell count; transaminase assays; renal function tests and a urine dipstick; assays of RFs, ACPA, and anti-nuclear antibodies; and screening tests for hepatitis B and C $[1,3,14]$. Auto-antibodies are major keys to the diagnosis. Published evidence supports good diagnostic performance of ACPAs and, to a lesser extent, RFs [4]. Of the many available auto-antibody assay methods, those most widely used at present and recommended in France by the HAS are as follows: for RFs, enzyme-linked immunosorbent assay (ELISA) or nephelometry to assay the IgM isotype; and for ACPA, ELISA to assay anti-cyclic citrullinated peptide antibodies [14]. 
At present, the criteria most widely used in patients with early arthritis are those developed jointly by the ACR and EULAR in 2010. Initially designed for classification purposes, these criteria can assist in the diagnosis of RA in difficult cases [28]. The ACR/EULAR criteria can be applied only to patients with clinical synovitis in at least one joint and no other diagnosis likely to explain the symptoms. In addition, patients with typical erosive disease on standard radiographs can be classified immediately as having RA, without applying the ACR/EULAR criteria. These last were designed as classification criteria and not as diagnostic criteria but can nevertheless provide useful diagnostic assistance provided they are not substituted for clinical judgment.

\subsubsection{Treatment targets and management organization}

\section{Recommendation 2: As soon as RA is diagnosed, disease-modifying treatment must be} initiated.

This recommendation is unchanged compared to 2014.

Initiating DMARD therapy as early as possible is a central tenet of the management of recent-onset RA, which is a therapeutic emergency. The 2016 EULAR recommendations describe the first 3 months of the disease as a therapeutic window of opportunity during which DMARD therapy should ideally be initiated [3]. Recent data consistently indicate that treatment initiation within 3 months after symptom onset is associated with improvements not only in clinical outcomes (achieving a remission, obtaining a treatment response, and minimizing functional impairments), but also in radiographic outcomes (limitation of structural disease progression, prevention of erosion development) [5,29]. Given these data, early DMARD therapy initiation is also recommended, before diagnostic confirmation is obtained, in patients with early undifferentiated arthritis at risk for progression to RA (highly active disease, positive tests for ACPAs and/or RFs, structural lesions) [3]. 
Recommendation 3. The treatment target is achieving and maintaining a remission or, at least, minimal disease activity. A clinical remission is defined as the absence of signs and symptoms of significant inflammatory activity.

The first part of this recommendation has been modified by the addition of remission maintenance to the treatment goals. Compared to 2014, this recommendation has also been simplified, by removing "in every patient, with the goal of preventing structural damage progression and the development of disabilities", which the task force felt was stating the obvious.

The goal of RA treatment is to provide patients with the best possible quality of life over the long term by controlling their symptoms, preventing structural damage, and allowing normal social and occupational activities. Convincing evidence exists that achieving a clinical remission or, to a lesser extent, minimal disease activity, is associated with less structural progression and less functional impairment [30]. Some data suggest that achieving an early and prolonged remission may diminish mortality [31].

A clinical remission is defined as the absence of signs or symptoms indicating significant inflammatory activity. These signs and symptoms include those detected by the medical interview, physical examination, and laboratory tests (inflammation markers) (see also recommendation 4). Recent published data demonstrate that achieving a clinical remission is at least as relevant as achieving an ultrasonographic remission. The randomized trials TASER and ARTIC, as well as observational data from everyday practice (RA BIODAM) found no evidence that ultrasonographic monitoring improved clinical or structural outcomes, and routine ultrasonography increases both the risk of overtreatment and management costs [32-34]. 
Achieving a clinical remission should therefore be the main treatment target in all patients with RA. Nevertheless, a remission is difficult to achieve in patients who have longstanding RA with major structural damage, in whom achieving minimal disease activity is an acceptable alternative.

In every case, the treatment target should be selected jointly with the patient. A treatment program is then established according to the previous treatment history, comorbidities, and risks related to the patient and drugs. Thus, minimal disease activity may seem preferable over a remission at all costs, for instance in patients who have failed several treatment lines or are at high risk for infection. On the opposite, the presence of comorbidities related to chronic inflammation, such as cardiovascular disease, may tip the balance in favor of more stringent treatment goals.

Clinical remission maintenance is a key concept that governs the follow-up strategy. In the 2016 EULAR recommendations, a remission is considered to be sustained if it has lasted 3 to 6 months [30]. Once a sustained remission is achieved, patients can be followed-up at longer intervals (see recommendation 5).

\section{Recommendation 4. Disease activity should be measured using validated composite criteria,} including joint indices.

This recommendation is unchanged compared to 2014. Several validated composite criteria are available for quantifying disease activity. They provide numerical scores that can be used to define the two treatment goals, i.e., remission and minimal disease activity. However, differences exist across available criteria. Thus, criteria such as the Disease Activity Score on 28 joints or DAS28 (with remission defined as DAS28-ESR $<2.6$ and minimal disease activity as $2.6 \leq \mathrm{DAS} 28-\mathrm{ESR} \leq 3.2$ ) are permissive, as they may indicate a remission despite the persistence of clinical synovitis in one or more joints [35]. Importantly, 
no cutoff for defining a remission has been established for the DAS28-CRP, and applying the DAS28-ESR cutoffs to the DAS28-CRP overestimates clinical remission rates, since the DAS28-CRP is even more permissive than the DAS28-ESR [36].

The criteria selected by the EULAR and ACR to define a remission are more stringent. They include:

- the Boolean-based criterion, with remission defined as values $\leq 1$ for the swollen joint count, patient global assessment of disease activity on a visual analog scale, and CRP in $\mathrm{mg} / \mathrm{dL}$;

- the Simplified Disease Activity Index or SDAI, with remission defined as $\mathrm{SDAI} \leq 3.3$ and minimal disease activity as $3.3<\mathrm{SDAI} \leq 11$;

- the Clinical Disease Activity Index or CDAI, with remission defined as $\mathrm{CDAI} \leq 2.8$ and minimal disease activity as $2.8<\mathrm{CDAI} \leq 10$; the $\mathrm{CDAI}$ has no laboratory items and provides very similar results to those obtained with the SDAI $[35,36]$.

The DAS28-ESR, SDAI, and CDAI seem to classify patients similarly for minimal disease activity but not for remission [37].

Any of these composite criteria that include a joint item can be used to monitor patients with RA. In addition, the evaluation of disease activity should combine the various items used in the composite criterion and the presence of synovitis or tenosynovitis at sites that may not be taken into account by the composite criterion, such as the feet.

In patients with early RA treated by a conventional synthetic DMARD (csDMARD), the EULAR/ACR definitions of remission (Boolean and SDAI) may be used preferentially, since persistent synovitis despite a DAS28 remission is associated with radiographic disease progression in this situation $[38,39]$. On the opposite, EULAR/ACR remission criteria are difficult to achieve in patients who have long-standing RA with joint destruction or 
comorbidities that interfere with the evaluation (e.g., fibromyalgia, osteoarthritis, or any disease that elevates the laboratory markers of inflammation).

In patients treated with IL-6 pathway antagonists, using the DAS28-ESR or DAS28CRP to evaluate the clinical response may not be optimal. Indeed, laboratory markers of inflammation weigh heavily on the scores produced by both DAS28 versions but are virtually always decreased by the biological effects of IL-6 inhibition [40].

Recommendation 5. Follow-up should be provided by a rheumatologist at closely spaced intervals (every 1 to 3 months) as long as the disease is active. Treatment adjustments are in order in patients who fail to improve within 3 months or to achieve their treatment target within 6 months.

For this recommendation, the only change compared to 2014 is the added information that follow-up should be provided by a rheumatologist.

Once the treatment target has been selected, follow-up designed to achieve tight disease control should be provided in order to achieve it rapidly, if needed via treatment adjustments. Sound evidence exists that tight disease control based on a composite disease activity criterion such as the DAS28 is associated with higher remission rates and shorter times to remission compared to standard care [30,41,42]. Thus, visits at intervals of 1 to 3 months (once a month in patients with high disease activity) are recommended until a remission or minimal disease activity is achieved then sustained for 3-6 months. The interval between follow-up visits can then be increased to 6 months (Figure 2).

A significant improvement after 3 months is the first indication of a treatment response and should be evaluated based on the variation in the selected composite criterion.

In addition to composite criteria for joint disease activity, annual monitoring of the functional impact of the disease using the Health Assessment Questionnaire (HAQ) is 
recommended, since preventing functional impairments is among the treatment objectives. Although improvements in patient-reported outcomes (PROs) are now used routinely in clinical trials, whether PROs should be used to determine whether treatment intensification is in order remains to be evaluated.

The 2014 SFR recommendations stated that structural disease progression should be monitored by obtaining standard radiographs of the hands and feet every 6-12 months the first year, annually for the next 3-5 years, and subsequently at longer intervals and whenever the treatment regimen is changed. Structural disease progression in patients with RA is markedly diminished by adjusting the treatment according to the tight disease control strategy, using stringent remission criteria such as those recommended by the EULAR and targeted treatments including biologic DMARDs (bDMARDs) and targeted synthetic DMARDs (tsDMARDs) $[43,44]$. Consequently, radiographic monitoring plays a pivotal role early in the disease, if residual clinical activity persists during follow-up, and whenever the treatment regimen is changed. Radiographs are probably less important in patients on targeted treatment who achieve a clinical remission with no synovitis. The usefulness of other imaging techniques such as ultrasonography and magnetic resonance imaging for monitoring structural disease progression remains to be demonstrated.

\subsubsection{First-line treatment (Figure 3)}

\section{Recommendation 6. Methotrexate is the first-line DMARD in patients with active RA,} starting at a dosage of at least $10 \mathrm{mg} /$ week then reaching the optimal dosage within no more than 4-8 weeks.

The difference with the 2014 recommendation 6 is that the starting dosage is specified.

Methotrexate is the first-line DMARD in patients with active RA. The starting dosage should be at least $10 \mathrm{mg} /$ week and the objective to reach the optimal dosage of 10 to 30 
$\mathrm{mg} /$ week within 4-8 weeks [45]. Although the maximal dosage can be used from the outset if deemed necessary by the rheumatologist, some evidence suggests that a gradual dosage increase may be associated with a better safety profile [46]. The optimal dosage varies with the efficacy and tolerance of the drug and with the individual patient profile. Asian patients should receive lower dosages (the maximal allowed dosage is $20 \mathrm{mg} /$ week in China and 16 $\mathrm{mg} /$ week in Japan).

In the event of an inadequate treatment response or failure to tolerate methotrexate, subcutaneous administration of the drug can be considered. For a given dosage, the subcutaneous route produces serum drug levels that are higher by $2.5-5 \mathrm{mg} /$ week compared to the oral route [47]. However, the higher cost of subcutaneous methotrexate should also be taken into consideration. Published data indicate that patients treated with methotrexate should receive at least $10 \mathrm{mg} /$ week of supplemental folic acid [48].

Combining methotrexate with other csDMARDs does not seem superior over methotrexate monotherapy in patients with early RA [49-51] and is associated with higher adverse event rates. Such combinations are therefore not recommended for the first-line treatment of RA.

In several recent studies, combining methotrexate with a bDMARD was superior over methotrexate alone for the first-line treatment of RA [52-55]. However, methotrexate was used without glucocorticoid therapy in these studies. In contrast, the IDEA randomized trial showed that methotrexate combined with infliximab was not better than methotrexate combined with $250 \mathrm{mg}$ of methylprednisolone as a single intravenous dose [56]. Furthermore, routinely adding a bDMARD for the first-line treatment would result in overtreatment of those patients who would have achieved their treatment target with methotrexate alone and, therefore, to unnecessary increases in both risks to patients and healthcare costs. Consequently, the use of a bDMARD for the first-line treatment of RA is 
not recommended. On the other hand, the indications of adding a glucocorticoid to methotrexate are broad (see recommendation 8).

\section{Recommendation 7. In DMARD-naive patients who have contraindications or early} intolerance to methotrexate, leflunomide and sulfasalazine are good alternatives.

This recommendation is unchanged compared to 2014. Methotrexate has few contraindications. Among them are pregnancy, absence of effective contraception, severe kidney dysfunction, and clinically significant liver disease. Contraindications related to the lung are exceedingly rare. Leflunomide and sulfasalazine have been proven effective on both clinical and structural parameters [7]. Leflunomide is used in a dosage of $20 \mathrm{mg} / \mathrm{day}$; pregnancy is also a contraindication to the use of this drug. Sulfasalazine is given in increasing dosages up to 2-3 g/day and can be given during pregnancy. Hydroxychloroquine can be combined with other csDMARDs, particularly given its possible metabolic and cardiovascular benefits in patients with RA [57]. Hydroxychloroquine monotherapy has little clinical efficacy and no structural effects and is therefore not recommended for the treatment of RA [7].

\section{Recommendation 8: While awaiting the effects of csDMARD therapy, oral or parenteral glucocorticoid therapy can be considered, in a low cumulative dosage, if possible for no longer than 6 months. The glucocorticoid dose should be tapered to nothing as promptly as possible.}

Compared to the 2014 recommendation 8 , this update specifies that glucocorticoid therapy can be considered at the initiation of csDMARD therapy, as opposed to targeted therapy (bDMARD or tsDMARD). With bDMARD and tsDMARD therapy, the argument for concomitant glucocorticoid therapy seems less convincing. That the glucocorticoid 
treatment should be brief, i.e., no longer than 6 months, to keep the cumulative dosage low, was already indicated in the 2014 recommendation and is reemphasized here. The updated recommendation specifies that the glucocorticoid can be given orally or parenterally. Finally, the updated version highlights the need for not only rapidly tapering the glucocorticoid dosage, but also stopping the glucocorticoid altogether as early as possible.

Recently published data demonstrate that glucocorticoid therapy is effective on both clinical and structural parameters and therefore still has a role to play in the treatment of RA $[5,7,58,59]$. In addition, new evidence suggests an improved safety profile when glucocorticoids are used for a short period and in low dosages [5,8,58,60,61]. Nevertheless, and keeping in mind the bias that stems from the preferential use of glucocorticoids in patients with high disease activity, new studies continue to supply evidence of the toxicity of long-term glucocorticoid therapy, even in low dosages, with increased risks of cardiovascular disease, infections, and osteoporosis $[5,8,62,63]$. Given the risk/benefit ratio of glucocorticoids, the task force considered that glucocorticoid therapy can be considered only in the lowest possible cumulative dose and for the shortest possible time. The cumulative dose concept is consistent with the initial use of high dosages given orally, intramuscularly, or intravenously followed by a rapid taper $[58,64,65]$. Intraarticular glucocorticoid injections also seem beneficial when used in combination with csDMARD therapy [5]. The task force selected 6 months as the desirable maximum duration of glucocorticoid therapy. Reducing this maximal duration to 3 months was suggested by several review panel experts. In keeping with the latest EULAR recommendations, the task force recommends routinely considering glucocorticoid therapy when starting a csDMARD for the first-line treatment or subsequent treatment modifications, although the evidence that glucocorticoid therapy benefits disease control comes chiefly from studies of patients with early RA [2]. Finally, the task force recommends that glucocorticoids be used only based on 
a risk/benefit ratio assessment in each individual patient and only in combination with the routine application of measures designed to prevent adverse effects (see recommendation $15)$.

\subsubsection{Second and subsequent treatment lines (Figure 3)}

Recommendation 9: In patients with an inadequate response or intolerance to methotrexate, the treatment must be optimized.

In patients with adverse prognostic factors, add-on bDMARD or tsDMARD therapy can be considered, using a TNF $\alpha$ antagonist, abatacept, an IL-6 pathway antagonist, a JAK inhibitor, or, under specific circumstances, rituximab.

In patients without adverse prognostic factors, a switch to another csDMARD (leflunomide, sulfasalazine) or the combination of several csDMARDs can be considered; if this strategy fails or is contraindicated, targeted therapy (with a bDMARD or tsDMARD) should be considered.

The 2014 version of this recommendation has been altered to insist on the need for optimizing the DMARD regimen if the response is inadequate ("must be optimized"). Furthermore, tsDMARDs are mentioned in addition to bDMARDs. Finally, the csDMARD combination (previously methotrexate/sulfasalazine/hydroxychloroquine) is no longer specified.

In patients who have an inadequate response after 3 months or have not achieved their treatment target after 6 months, the treatment must be optimized (see recommendations 3 and 5). The optimization strategy varies depending on whether the following predictors of a poor prognosis or poor treatment response are present:

- early erosions

- $\quad$ RFs and ACPA, notably in high titers $(\geq 3 \mathrm{~N})$ 
- persistent moderate-to-high disease activity despite csDMARD therapy, with high ESR and CRP values and/or a high swollen joint count

- failure of $\geq 2$ csDMARDs

The above-listed factors of adverse prognostic significance were identified in recently published studies as risk factors for structural progression $[66,67]$. No studies were specifically designed to compare the efficacy of csDMARDs and targeted therapies depending on the presence or absence of factors of adverse prognostic significance. Nevertheless, early erosions, auto-antibodies, and high disease activity are strongly associated with worse structural disease progression [66], and targeted therapies have greater structural effects than do csDMARDs. Post hoc analyses have confirmed that adding a bDMARD to methotrexate provides greater benefits in patients with vs. without factors of adverse prognostic significance [67,68]. In everyday practice, benefits were limited from using another csDMARD in patients with moderate-to-high disease activity despite csDMARD therapy [69]. Compared to the 2014 recommendations, failure of $\geq 2$ csDMARDs has been added. This factor predicts a poor treatment response rather than a poor prognosis. The task force considered that failure of two csDMARDs is associated with a very low likelihood of a response to third DMARD and consequently indicates targeted therapy [68].

In patients with factors of adverse prognostic significance, any form of targeted therapy can be used (bDMARD or tsDMARD). Neither head-to-head comparisons [70-72] nor metaanalyses found any consistent evidence of differences in efficacy across targeted therapies given in combination with methotrexate $[6,73,74]$. Among targeted therapies, bDMARDs may deserve preference based on the longer experience with these drugs and availability of long-term registry data on treatment safety $[8,75]$. Nevertheless, safety data on tsDMARDs are favorable [76,77], and baricitinib may be more effective than adalimumab in combination with methotrexate [72]. Rituximab has not been licensed for first-line targeted 
therapy but can be considered in specific situations, such as a history of cancer within the past 5 years, latent tuberculosis with a contraindication to prophylactic antituberculosis drug therapy, and a history of lymphoma or demyelinating disease, since these conditions are known to respond to rituximab $[78,79]$. Abatacept is another alternative in patients with demyelinating disease [80].

In patients with no factors of adverse prognostic significance, switching to or adding another csDMARD can be considered. In this situation, as with first-line treatment, concomitant glucocorticoid therapy may expedite disease control. Combinations of csDMARDs (e.g., methotrexate/sulfasalazine/hydroxychloroquine, methotrexate/sulfasalazine, or methotrexate/hydroxychloroquine) have not been proven superior over methotrexate alone when glucocorticoid therapy is used in both groups (see recommendation 6). They may however deserve consideration in patients without factors of adverse prognostic significance who fail methotrexate therapy or have contraindications, notably infectious conditions, to targeted therapy [81,82].

When methotrexate therapy must be discontinued within the first 3 months due to intolerance, a switch to another csDMARD (leflunomide or sulfasalazine) should be preferred over targeted therapy, as indicated in recommendation 7.

\section{Recommendation 10. All targeted therapies (bDMARDs and tsDMARDs) are best used in combination with methotrexate.}

Compared to the 2014 version of this recommendation, the term "targeted therapies" is used instead of "biologics", to include tsDMARDs.

Adding methotrexate to targeted therapy provides greater clinical and radiographic efficacy compared to targeted therapy alone. This added efficacy has been demonstrated for all bDMARDs [6,83], including tocilizumab, with which the combination produced better 
numerical results [84-86]. The same applies to JAK inhibitors. Thus, in the ORAL strategy, the tofacitinib-methotrexate combination induced an ACR50 response at 6 months in $46 \%$ of patients with RA, compared to $38 \%$ with tofacitinib alone [70]. In the RA-BEGIN randomized trial, the baricitinib-methotrexate combination induced a DAS28-ESR remission at 12 months in $30 \%$ of patients versus $22 \%$ with baricitinib alone, and structural efficacy was also greater with the combination $(79.9 \%$ vs. $68.8 \%$ of patients without radiographic progression after 1 year) [87]. Consequently, all bDMARDs and tsDMARDs should be used in combination with methotrexate whenever possible.

In the randomized CONCERTO trial, adding methotrexate $10 \mathrm{mg} /$ week to adalimumab was as effective as adding methotrexate $20 \mathrm{mg} /$ week and more effective than adding methotrexate 2.5 or $5 \mathrm{mg} /$ week [88]. The randomized noninferiority MUSICA trial demonstrated greater efficacy of the adalimumab-methotrexate combination when the methotrexate dosage was $20 \mathrm{mg} /$ week rather than $7.5 \mathrm{mg} /$ week [89]. Thus, in patients on targeted therapy, a decrease in the methotrexate dosage can be considered provided the dosage remains at or above $10 \mathrm{mg} /$ week.

In patients with contraindications or intolerance to methotrexate, targeted therapy can be combined with leflunomide or sulfasalazine. In several studies, TNF $\alpha$ antagonist therapy proved similarly effective whether methotrexate or leflunomide was the combination drug. Data from the British Society for Rheumatology Biologics Register (BSRBR) of RA patients indicate a lower risk of TNF $\alpha$ antagonist therapy discontinuation when sulfasalazine is given also than when the TNF $\alpha$ antagonist is used alone, although the risk is higher than with combined methotrexate therapy [92].

In patients who cannot be given a csDMARD in combination with targeted therapy, TNF $\alpha$ antagonist monotherapy is best avoided. Studies have consistently demonstrated decreased clinical efficacy of TNF $\alpha$ antagonist monotherapy compared to the TNF $\alpha$ 
antagonist-methotrexate combination, due in part to an immune response against the TNF $\alpha$ antagonist, which is more common in the absence of methotrexate [93]. The most convincing data on the efficacy of targeted therapies used alone have been obtained with IL6 receptor antagonists and tsDMARDs. Tocilizumab and JAK inhibitors used alone produced response rates similar to those achieved with combined methotrexate, both in randomized trials and in cohort studies $[70,87,94,95]$. Furthermore, in the ADACTA and MONARCH randomized trials, tocilizumab and sarilumab, respectively, were more effective than adalimumab monotherapy [96,97]. Data from the TOCERRA registry indicate similar efficacy and drug continuation rates with tocilizumab monotherapy and with TNF $\alpha$ antagonist-combinations [95,97].

Neither etanercept nor abatacept induce the production of anti-drug antibodies. In some of the randomized controlled trials, etanercept monotherapy, although clinically effective, was less so than the etanercept-methotrexate combination and showed greater structural efficacy compared to csDMARDs $[98,99]$. Observational data support a therapeutic effect of abatacept, but this drug is not licensed for use as monotherapy $[100,101]$

Thus, in patients who cannot take csDMARDs, IL-6 receptor antagonists and JAK inhibitors may exhibit advantages over the other targeted therapies, notably TNF $\alpha$ antagonists, whose initiation as monotherapy should be avoided.

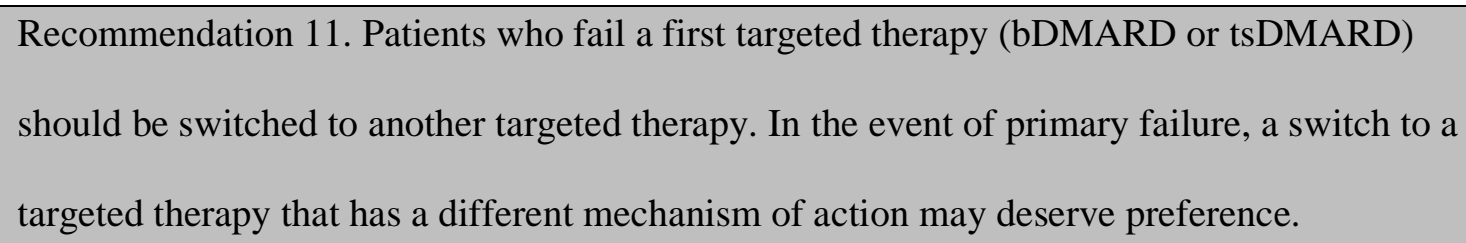


Compared to the 2014 recommendations, the term "targeted therapy" has been substituted for "biological agent" to include tsDMARDs, and a preference for switching to a drug that has a different mechanism of action in the event of primary failure has been added.

In patients having failed a first TNF $\alpha$ antagonist, most studies found that efficacy was similar across targeted therapies, i.e., between switching to another TNF $\alpha$ antagonist and switching to a drug with a different mechanism of action $[6,102,103]$. In the French ROC randomized trial, the EULAR response rate was higher when patients were switched to a drug with a different mechanism of action after failure of a first TNF $\alpha$ antagonist [104]. However, this difference was chiefly ascribable to a strong EULAR response in patients given tocilizumab (48\% of patients in the "other mechanism of action" group), which consistently decreases the levels of laboratory markers of inflammation. Therefore, either a drug that has the same mechanism of action (e.g., another TNF $\alpha$ antagonist) or a drug with a different mechanism of action can be used interchangeably. To date, no published evidence exists about the efficacy of a second JAK inhibitor after failure of a first tsDMARD or about the efficacy of a second IL-6 receptor antagonist after failure of tocilizumab.

In the specific case of primary treatment failure, i.e., failure to achieve sufficient improvement after 3 months or the treatment target after 6 months, a switch to a drug with a different mechanism of action seems desirable. Data from cohort studies suggest that a treatment directed to a different target is more effective after failure of a first TNF $\alpha$ [105]. Nonetheless, in the randomized EXXELERATE trial comparing certolizumab to adalimumab, both given with methotrexate, switching to a second TNF $\alpha$ antagonist after primary failure of a first $\mathrm{TNF} \alpha$ antagonist produced a response rate that was satisfactory, albeit lower than with the first TNF $\alpha$ antagonist [106].

Importantly, treatment adherence must be monitored. Poor treatment adherence is a common cause of treatment failure. Adherence to methotrexate therapy varies considerably 
[107]. Treatment adherence is influenced by patient beliefs, which in turn can be influenced by TPE [108].

\subsubsection{Managing disease remission}

\section{Recommendation 12: In patients who have a sustained remission without glucocorticoid} therapy, a decrease in the targeted therapy dosage must be considered.

In 2014, this recommendation was less restrictive regarding glucocorticoid therapy, as DMARD dosage de-escalation could be considered either after glucocorticoid discontinuation or after glucocorticoid dosage tapering to no more than $5 \mathrm{mg} / \mathrm{day}$. The task force elected to require discontinuation of glucocorticoid therapy to emphasize the importance of weaning the patient off glucocorticoids in the event of a remission. Furthermore, in the new version of this recommendation, the term "targeted therapy" is used instead of "biological agent" in order to include tsDMARDs. Finally, the task force considered that the importance of DMARD dosage de-escalation should be highlighted by using the term "must" instead of "can".

A sustained remission is generally defined as a remission that lasts at least 3 to 6 months $[1,2]$. Inflammation and joint destruction may not evolve in lockstep, and some patients may continue to exhibit structural disease progression despite a clinical remission. Consequently, radiographs should be obtained before and during the dosage taper to check for structural disease progression [109]. When a sustained remission is achieved, any glucocorticoid therapy must be discontinued before DMARD de-escalation can be considered. In specific situations such as long-standing RA, DMARD de-escalation may be considered even when complete glucocorticoid discontinuation proves impossible, provided the glucocorticoid dosage is first decreased to no more than $5 \mathrm{mg} /$ day. Ultrasonography to 
check the absence of residual subclinical disease activity has not been found relevant to date as a means of guiding DMARD de-escalation (see recommendation 3).

Studies have shown that after abrupt bDMARD discontinuation, the remission or minimal disease activity is maintained in only a small proportion of patients [6]. This strategy is therefore not recommended. Recent published evidence shows, in contrast, that targeted therapy de-escalation (by gradually decreasing the dosage or increasing the dosing interval) according to disease activity allows remission or minimal disease activity maintenance in a significant proportion of patients [6]. Thus, recently published data on the 3-year extension phases of the STRASS and DRESS randomized trials demonstrated that changes in disease activity parameters (clinical, and radiographic in STRASS) were not significantly different between patients who decreased their TNF $\alpha$ antagonist dosage and those who continued on the same dosage after achieving a remission (STRASS) or minimal disease activity (DRESS) $[110,111]$. Studies of non-TNF $\alpha$ antagonist bDMARDs and of JAK inhibitors remain scarce but seem to indicate similar conclusions [112-114]. Returning to the initial targeted therapy dosage or dosing interval in the event of a flare restored adequate disease control in over $80 \%$ of patients $[112,114,115]$.

Most of the studies evaluating bDMARD or tsDMARD de-escalation strategies were conducted in patients who were also receiving csDMARD therapy. Consequently, targeted therapy de-escalation after a remission is achieved should be preferentially considered in patients who are also taking a csDMARD. Other predictive factors are the time to remission and the duration and depth of the remission [116,117]. Achieving minimal disease activity does not seem sufficient to initiate targeted therapy de-escalation [116].

Recommendation 13: In patients who have a sustained remission without targeted therapy or glucocorticoid therapy, csDMARD de-escalation can be considered. 
The wording of this recommendation is slightly different from that used in 2014, to indicate that csDMARD de-escalation should be considered only in patients who are not receiving glucocorticoid therapy and who are not, or no longer, taking targeted therapies. Otherwise, de-escalation of the targeted therapy should be considered first. In addition, the sentence fragment "as a medical decision shared by the patient and physician" has been removed, as the task force considered that the decision-sharing concept is stated in general principle A and therefore applies to all 15 recommendations.

De-escalation of csDMARD therapy can be considered in patients who are in sustained remission without glucocorticoid therapy (see recommendation 12). Few studies have focused specifically on csDMARD de-escalation [116]. As with targeted therapies, deescalation adapted to the level of disease activity seems preferable over abrupt discontinuation, which carries a high risk of relapse [118,119]. Given that remissions without treatment are uncommon, sudden csDMARD discontinuation can only be considered in specific cases [116].

\subsubsection{Global patient management}

\section{Recommendation 14: Treatment selection and adjustment should factor in a number of considerations in addition to measured disease activity, such as structural disease progression, comorbidities, tolerance of the drugs, treatment adherence, and the patient's wishes.}

The only change compared to 2014 is the addition of treatment adherence.

Patient adherence to the therapeutic project is crucial. In addition to full adherence, patient involvement and persistence in applying the pharmacological and nonpharmacological therapeutic measures must be obtained. Recommendations about adherence to pharmacological therapy of patients with chronic inflammatory joint disease 
were presented in 2017 by a French task force during the Rheumatology Expert Meetings (Rencontres d'Experts en Rhumatologie; Puyraimond-Zemmour D et al., abstract SAT0691, EULAR 2018). These recommendations include evaluating patient adherence at each visit and, in the event of nonadherence, implementing a specific intervention (TPE, motivational interview). The tolerance of the prescribed medications should also be factored into medication selection and adjustment given its major influence on adherence to pharmacological therapy.

In addition, this recommendation serves as a reminder that all the characteristics of the patient, including for instance any comorbidities or a wish to conceive, should be taken into consideration when making treatment decisions. Thus, the comorbidity profile may influence both the choice of the treatment target (see recommendation 3) and the treatment response in patients with RA, due to pathophysiological interactions between concomitant diseases, effects on the evaluation of disease activity, or polypharmacy [120].

Finally, as indicated in recommendation 12 , some patients continue to experience structural disease progression despite a low level of clinical disease activity. Consequently, the radiographic findings should be taken into account when making treatment decisions.

\section{Recommendation 15. Screening for and periodic evaluations of comorbidities and their risk factors, as well as periodic evaluations of their management, should be provided. The management program should include lifestyle advice (e.g., about regular physical activity, smoking cessation, and a healthy diet) and immunization updates.}

The previous recommendation 15 , in which only comorbidities were mentioned, has been replaced by general principle $\mathrm{C}$. The current recommendation has been added to detail the management of comorbidities. 
In patients with RA, the cardiovascular risk level is high, similar to that associated with diabetes [121]. This excess risk is ascribable to both chronic inflammation and exposure to medications such as glucocorticoids and nonsteroidal antiinflammatory drugs [122]. Achieving control of the inflammatory process by using DMARDs, most notably targeted therapies, is associated with a decrease in the cardiovascular risk [122].

Cardiovascular risk management involves evaluating the cardiovascular risk and screening for conventional cardiovascular risk factors (smoking, diabetes, hypertension, dyslipidemia, and obesity); interventions to control conventional cardiovascular risk factors; and control of the inflammatory process. As suggested by EULAR, the rheumatologist is in the best position to organize cardiovascular risk factor screening and management in patients with RA [123]. The cardiovascular risk is best evaluated using HeartScore ${ }^{\circledR}$. The level of cardiovascular risk dictates the LDL-cholesterol target, the frequency of screening tests, and whether cardiologist referral is in order. EULAR also suggests the use of Doppler ultrasonography of the supra-aortic vessels, as the presence of carotid artery plaque indicates a high level of cardiovascular risk. Carotid artery plaque is found in nearly $60 \%$ of patients with RA [124].

Screening for and management of comorbidities is not limited to an evaluation of the cardiovascular risk. Patients with RA are also at increased risk for infection, lung disease, malignancy, gastrointestinal disease, osteoporosis, and depression, which may be induced by the disease or its treatments [125]. In addition, screening for these conditions is poorer in patients with RA than in the general population. The screening tests for malignancies recommended in the general population should be performed, oral health checked, and immunizations updated. In addition to the immunizations recommended in the general population, the influenza vaccine should be administered annually, the diphtheria-poliotetanus vaccine every 10 years, and the pneumococcal vaccine every 5 years in patients with 
RA [126]. Patients with no history of pneumococcal immunization should receive a dose of the 13 -valent conjugated vaccine followed at least 8 weeks later by a dose of the 23 -valent nonconjugated vaccine. Patients who previously received only the 23 -valent nonconjugated vaccine can be given a dose of the 13-valent conjugated vaccine if the previous immunization was performed more than 1 year earlier; otherwise, they can be given a second injection of the 23-valent nonconjugated vaccine at least 5 years after the first. Patients having previously received the 13 -valent conjugated/23-valent nonconjugated sequence can be given a second injection of the 23 -valent nonconjugated vaccine at least 5 years after the first. Other immunizations should be given according to the schedule recommended for the general population.

Maintaining good oral health decreases the risk of infection. In addition, due to the associations that link periodontal disease and RA [127,128], improving oral health may benefit the course of RA [129].

A variety of screening modalities can be used. Rheumatologists may implement a screening program over several visits. Alternatively, the screening tests may be done at a healthcare facility over a single day [130] or performed in part by a specialized nurse [131]. The latest French and European recommendations about screening for cardiovascular and other comorbidities have been collected into a single document to facilitate their application by rheumatologists [132].

Lifestyle advice should be provided as part of the management of RA. Programs designed to promote a healthy lifestyle have been shown to decrease the cardiovascular risk [133]. Patients should be advised to engage in regular physical activity, which may also decrease pain and improve quality of life and morale [134]. Smoking cessation should be recommended to decrease the cardiovascular risk [135]. Smoking cessation may also be associated with decreased disease activity and a better treatment response [136,137]. Finally, 
a healthy diet is recommended. The Mediterranean diet and a sufficient intake of omega-3 fatty acids (oily fish, fish oil, or supplements) deserve to be recommended as they are associated with a decreased cardiovascular risk [138] and with a small beneficial effect on disease activity in patients with RA $[139,140]$. In contrast, diets that exclude certain components such as gluten or lactose have exhibited no clinical efficacy (and no preclinical efficacy in animal models). A gluten-free diet may be associated with an increased cardiovascular risk [141,142] and a daily diet with an increased risk of osteoporosis. Both these diets should therefore be avoided.

Thus, patients with RA should be offered a global management program (Figure 4).

\section{Discussion}

Research continuously provides new information about various domains related to RA including the development of new treatments, the devising of therapeutic strategies, and the use of nonpharmacological treatments. This strong dynamic requires that management recommendations be updated regularly to ensure that healthcare professionals involved in caring for patients with RA can tailor their practice to the most recent knowledge. Therefore, in 2018, the SFR decided to update its previous recommendations issued in 2014.

This new set of SFR recommendations comprises four general principles and 15 recommendations covering the full range of RA management domains including the diagnosis, pharmacological and nonpharmacological treatments, patient follow-up, and the management of comorbidities.

The new recommendations intersect at many points with those issued in 2014 , notably regarding the central role for the rheumatologist in the management of patients with RA; the need for a therapeutic partnership between the patient and the rheumatologist; the importance of providing a global management program encompassing both the RA and any 
comorbidities and relying not only on medications, but also on nonpharmacological means such as rehabilitation therapy and TPE; and, finally, the need for attention to the individual and societal costs of RA. Finally, as was the case in 2014, the updated recommendations highlight the importance of establishing the diagnosis and starting the treatment of RA as early as possible.

However, the 2018 recommendations also differ in several ways from those issued in 2014. The tsDMARDs recently introduced into the French market are discussed. The task force decided to give equal importance to JAK inhibitors and to bDMARDs. Another difference compared to 2014 is the statement that switching to a medication with a different mechanism of action in the event of primary treatment failure deserves preference. Finally, greater emphasis is placed on promoting a healthy lifestyle and managing the comorbidities as a full-fledged component of the management of RA.

Most of the recommendations are based on a high level of evidence, obtained a high level of agreement, and received strong grades. Except for general principle B, the level of agreement with each general principle and recommendation was lower among review panel members than among task force members (Table 2), probably in part because the review panel did not have access to the full text of the recommendations. The comments made by the review panel usually involved issues that had been discussed by the task force and developed in the text accompanying each recommendation. Given the continuing active research into RA, these recommendations will probably need to be updated in a few years.

\section{Disclosure of interest}

C. Daien has received honoraria from Abbvie, BMS, Novartis, Pfizer, Roche-Chugai, Sanofi, and UCB.

C. Hua has received honoraria from Abbvie, BMS, Novartis, and Pfizer. 
C. Gaujoux-Viala has received honoraria from Abbvie, BMS, Celgene, Janssen, Lilly, Medac, MSD, Nordic Pharma, Novartis, Pfizer, Sanofi, Schering, Roche- Chugai, and UCB. A. Cantagrel has received honoraria from AbbVie, BMS, Merck, Nordic Pharma, Novartis, Pfizer, Roche-Chugai, and UCB.

M. Dougados has participated as a consultant in meetings organized by Pfizer, Abbvie, Roche, UCB, BMS, Lilly, Janssen, and Novartis and his department has received research grants from Pfizer, Abbvie, Roche, UCB, BMS, Lilly, Janssen, and Novartis.

B. Fautrel has received honoraria from AbbVie, BMS, MSD, Nordic Pharma, Pfizer, RocheChugai, and UCB.

X. Mariette has received honoraria from BMS, Janssen, Novartis, Pfizer, and UCB.

C. Richez has received honoraria from Abbvie, BMS, Lilly, Medac, Merck, Nordic Pharma, Pfizer, Roche-Chugai, Sanofi, and UCB.

A. Saraux has received honoraria from Abbvie, BMS, Lilly, Merck, Pfizer, Roche-Chugai, Sanofi, and UCB.

D. Wendling has received honoraria from AbbVie, BMS, MSD, Pfizer, Roche Chugai, Amgen, Nordic, UCB, Sobi, Sanofi Aventis, Novartis, Janssen, Hospira, Celgene, Lilly, and Sandoz.

L. Gossec has received honoraria from Abbvie, BMS, Celgene, Janssen, Lilly, Novartis, Pfizer, Sanofi, and UCB.

B. Combe has received honoraria from Abbvie, BMS, Janssen, Lilly, Merck, Pfizer, RocheChugai, Sanofi, and UCB.

M. Dubremetz, N. Nayral, and G. Thibaud have no conflicts of interest to declare.

\section{Acknowledgments}


We thank the members of the review panel who read and commented on the recommendations:

Baudens G, Beauvais C, Berenbaum F, Berthelot J-M, Boumier P, Brocq O, Constantin A, Devauchelle-Pensec V, Dixneuf V, Fayet F, Flipo R-M, Gaudin P, Goeb V, Goupille P, Grange L, Hudry C, Jousse-Joullin S, Le Goff B, Marotte H, Mezieres M, Morel J, Perdriger A, Pham T, Pouplin S, Roth O, Ruyssen-Witrand A, Schaeverbeke T, Sellam J, Senbel E, Soubrier M, and 10 patients designated by the AFP RIC and ANDAR. 


\section{References}

[1] Gaujoux-Viala C, Gossec L, Cantagrel A, Dougados M, Fautrel B, Mariette X, et al. Recommendations of the French Society for Rheumatology for managing rheumatoid arthritis. Jt Bone Spine Rev Rhum 2014;81:287-97.

[2] Smolen JS, Landewé R, Bijlsma J, Burmester G, Chatzidionysiou K, Dougados M, et al. EULAR recommendations for the management of rheumatoid arthritis with synthetic and biological disease-modifying antirheumatic drugs: 2016 update. Ann Rheum Dis 2017;76:960-77.

[3] Combe B, Landewe R, Daien CI, Hua C, Aletaha D, Álvaro-Gracia JM, et al. 2016 update of the EULAR recommendations for the management of early arthritis. Ann Rheum Dis 2017;76:948-59.

[4] Hua C, Daien CI, Combe B, Landewe R. Diagnosis, prognosis and classification of early arthritis: results of a systematic review informing the 2016 update of the EULAR recommendations for the management of early arthritis. RMD Open 2017;3:e000406.

[5] Daien CI, Hua C, Combe B, Landewe R. Non-pharmacological and pharmacological interventions in patients with early arthritis: a systematic literature review informing the 2016 update of EULAR recommendations for the management of early arthritis. RMD Open 2017;3:e000404.

[6] Nam JL, Takase-Minegishi K, Ramiro S, Chatzidionysiou K, Smolen JS, van der Heijde D, et al. Efficacy of biological disease-modifying antirheumatic drugs: a systematic literature review informing the 2016 update of the EULAR recommendations for the management of rheumatoid arthritis. Ann Rheum Dis 2017;76:1113-36. doi:10.1136/annrheumdis-2016210713.

[7] Chatzidionysiou K, Emamikia S, Nam J, Ramiro S, Smolen J, van der Heijde D, et al. Efficacy of glucocorticoids, conventional and targeted synthetic disease-modifying 
antirheumatic drugs: a systematic literature review informing the 2016 update of the EULAR recommendations for the management of rheumatoid arthritis. Ann Rheum Dis 2017;76:1102-7.

[8] Ramiro S, Sepriano A, Chatzidionysiou K, Nam JL, Smolen JS, van der Heijde D, et al. Safety of synthetic and biological DMARDs: a systematic literature review informing the 2016 update of the EULAR recommendations for management of rheumatoid arthritis. Ann Rheum Dis 2017;76:1101-36.

[9] Oxford Centre for Evidence-based Medicine - Levels of Evidence (March 2009). CEBM 2009. http://www.cebm.net/oxford-centre-evidence-based-medicine-levels-evidence-march2009/ (accessed April 24, 2016).

[10] Beauvais C. L'éducation thérapeutique pour la polyarthrite rhumatoïde : pourquoi, quand et comment ? Rev Rhum Monogr 2018;85:61-5.

[11] Zangi HA, Ndosi M, Adams J, Andersen L, Bode C, Boström C, et al. EULAR recommendations for patient education for people with inflammatory arthritis. Ann Rheum Dis 2015;74:954-62.

[12] Haute Autorité de Santé H. Recommandations. Education thérapeutique du patient. Définitions, finalités et organisation n.d. https://www.hassante.fr/portail/jcms/c_1241714/fr/education-therapeutique-du-patient-etp.

[13] Emery P, Breedveld FC, Dougados M, Kalden JR, Schiff MH, Smolen JS. Early referral recommendation for newly diagnosed rheumatoid arthritis: evidence based development of a clinical guide. Ann Rheum Dis 2002;61:290-7.

[14] Haute Autorité de Santé H. Recommandations professionnelle - Polyarthrite Rhumatoïde Synthèse des recommandations n.d. https://www.hassante.fr/portail/upload/docs/application/pdf/polyarthrite_rhumatoide__synthese_de_lensemble_des_recommandations.pdf. 
[15] Husberg M, Davidson T, Hallert E. Non-medical costs during the first year after diagnosis in two cohorts of patients with early rheumatoid arthritis, enrolled 10 years apart. Clin Rheumatol 2017;36:499-506.

[16] Matsumoto T, Nishino J, Izawa N, Naito M, Hirose J, Tanaka S, et al. Trends in Treatment, Outcomes, and Incidence of Orthopedic Surgery in Patients with Rheumatoid Arthritis: An Observational Cohort Study Using the Japanese National Database of Rheumatic Diseases. J Rheumatol 2017;44:1575-82.

[17] Nystad TW, Fenstad AM, Furnes O, Havelin LI, Skredderstuen AK, Fevang B-T. Reduction in orthopaedic surgery in patients with rheumatoid arthritis: a Norwegian register-based study. Scand J Rheumatol 2016;45:1-7.

[18] ter Wee MM, Lems WF, Usan H, Gulpen A, Boonen A. The effect of biological agents on work participation in rheumatoid arthritis patients: a systematic review. Ann Rheum Dis 2012;71:161-71.

[19] Vanier A, Mariette X, Tubach F, Fautrel B, STRASS Study Group. Cost-Effectiveness of TNF-Blocker Injection Spacing for Patients with Established Rheumatoid Arthritis in Remission: An Economic Evaluation from the Spacing of TNF-Blocker Injections in Rheumatoid Arthritis Trial. Value Health J Int Soc Pharmacoeconomics Outcomes Res 2017;20:577-85.

[20] Gulácsi L, Brodszky V, Baji P, Kim H, Kim SY, Cho YY, et al. Biosimilars for the management of rheumatoid arthritis: economic considerations. Expert Rev Clin Immunol 2015;11 Suppl 1:S43-52.

[21] van Steenbergen HW, Aletaha D, Beaart-van de Voorde LJJ, Brouwer E, Codreanu C, Combe B, et al. EULAR definition of arthralgia suspicious for progression to rheumatoid arthritis. Ann Rheum Dis 2017;76:491-6. 
[22] Villeneuve E, Nam JL, Bell MJ, Deighton CM, Felson DT, Hazes JM, et al. A systematic literature review of strategies promoting early referral and reducing delays in the diagnosis and management of inflammatory arthritis. Ann Rheum Dis 2013;72:13-22.

[23] Colebatch AN, Edwards CJ, Østergaard M, van der Heijde D, Balint PV, D’ Agostino M-A, et al. EULAR recommendations for the use of imaging of the joints in the clinical management of rheumatoid arthritis. Ann Rheum Dis 2013;72:804-14.

[24] Forien M, Ottaviani S. Ultrasound and follow-up of rheumatoid arthritis. Jt Bone Spine Rev Rhum 2017;84:531-6.

[25] Nam JL, Hensor EMA, Hunt L, Conaghan PG, Wakefield RJ, Emery P. Ultrasound findings predict progression to inflammatory arthritis in anti-CCP antibody-positive patients without clinical synovitis. Ann Rheum Dis 2016;75:2060-7.

[26] Naredo E, Bonilla G, Gamero F, Uson J, Carmona L, Laffon A. Assessment of inflammatory activity in rheumatoid arthritis: a comparative study of clinical evaluation with grey scale and power Doppler ultrasonography. Ann Rheum Dis 2005;64:375-81.

[27] van der Heijde D, van der Helm-van Mil AH, Aletaha D, Bingham CO, Burmester GR, Dougados M, et al. EULAR definition of erosive disease in light of the 2010 ACR/EULAR rheumatoid arthritis classification criteria. Ann Rheum Dis 2013;72:479-81.

[28] Hua C, Combe B. Les nouveaux critères de classification ACR/EULAR 2010 pour un diagnostic plus précoce de la polyarthrite rhumatoïde. Rev Rhum Monogr 2017;84:337-42.

[29] van Nies JA, Tsonaka R, Gaujoux-Viala C, Fautrel B, van der Helm-van Mil AH. Evaluating relationships between symptom duration and persistence of rheumatoid arthritis: does a window of opportunity exist? Results on the Leiden early arthritis clinic and ESPOIR cohorts. Ann Rheum Dis 2015;74:806-12. 
[30] Smolen JS, Breedveld FC, Burmester GR, Bykerk V, Dougados M, Emery P, et al. Treating rheumatoid arthritis to target: 2014 update of the recommendations of an international task force. Ann Rheum Dis 2016;75:3-15.

[31] Scirè CA, Lunt M, Marshall T, Symmons DPM, Verstappen SMM. Early remission is associated with improved survival in patients with inflammatory polyarthritis: results from the Norfolk Arthritis Register. Ann Rheum Dis 2014;73:1677-82.

[32] Dale J, Stirling A, Zhang R, Purves D, Foley J, Sambrook M, et al. Targeting ultrasound remission in early rheumatoid arthritis: the results of the TaSER study, a randomised clinical trial. Ann Rheum Dis 2016;75:1043-50.

[33] Haavardsholm EA, Aga A-B, Olsen IC, Lillegraven S, Hammer HB, Uhlig T, et al. Ultrasound in management of rheumatoid arthritis: ARCTIC randomised controlled strategy trial. BMJ 2016;354:i4205.

[34] Sepriano A, Ramiro S, Landewe R, van der Heijde D, Ohrndorf S, FitzGerald O, et al. Abstract 2967: Adding Ultrasound to the Treat-to-Target Strategy Shows No Benefit in Achievement of Remission: Results from the Biodam Cohort. Arthritis Rheumatol 2017;Abstract Supplement:4222-3.

[35] Mack ME, Hsia E, Aletaha D. Comparative Assessment of the Different American College of Rheumatology/European League Against Rheumatism Remission Definitions for Rheumatoid Arthritis for Their Use as Clinical Trial End Points. Arthritis Rheumatol Hoboken NJ 2017;69:518-28.

[36] Smolen JS, Aletaha D, Gruben D, Zwillich SH, Krishnaswami S, Mebus C. Brief Report: Remission Rates With Tofacitinib Treatment in Rheumatoid Arthritis: A Comparison of Various Remission Criteria. Arthritis Rheumatol Hoboken NJ 2017;69:728-34.

[37] Fleischmann R, van der Heijde D, Koenig AS, Pedersen R, Szumski A, Marshall L, et al. How much does Disease Activity Score in 28 joints ESR and CRP calculations 
underestimate disease activity compared with the Simplified Disease Activity Index? Ann Rheum Dis 2015;74:1132-7.

[38] Aletaha D, Smolen JS. Joint damage in rheumatoid arthritis progresses in remission according to the Disease Activity Score in 28 joints and is driven by residual swollen joints. Arthritis Rheum 2011;63:3702-11.

[39] Kavanaugh A, Fleischmann RM, Emery P, Kupper H, Redden L, Guerette B, et al. Clinical, functional and radiographic consequences of achieving stable low disease activity and remission with adalimumab plus methotrexate or methotrexate alone in early rheumatoid arthritis: 26-Week results from the randomised, controlled OPTIMA study. Ann Rheum Dis 2013;72:64-71.

[40] Iking-Konert C, Aringer M, Wollenhaupt J, Mosch T, Tuerk S, Feist E, et al. Performance of the new 2011 ACR/EULAR remission criteria with tocilizumab using the phase IIIb study TAMARA as an example and their comparison with traditional remission criteria. Ann Rheum Dis 2011;70:1986-90.

[41] Schipper LG, Vermeer M, Kuper HH, Hoekstra MO, Haagsma CJ, Den Broeder AA, et al. A tight control treatment strategy aiming for remission in early rheumatoid arthritis is more effective than usual care treatment in daily clinical practice: a study of two cohorts in the Dutch Rheumatoid Arthritis Monitoring registry. Ann Rheum Dis 2012;71:845-50.

[42] Schipper LG, van Hulst LTC, Grol R, van Riel PLCM, Hulscher MEJL, Fransen J. Metaanalysis of tight control strategies in rheumatoid arthritis: protocolized treatment has additional value with respect to the clinical outcome. Rheumatol Oxf Engl 2010;49:2154-64.

[43] Landewé R, van der Heijde D, Klareskog L, van Vollenhoven R, Fatenejad S. Disconnect between inflammation and joint destruction after treatment with etanercept plus methotrexate: results from the trial of etanercept and methotrexate with radiographic and patient outcomes. Arthritis Rheum 2006;54:3119-25. 
[44] Smolen JS, Han C, van der Heijde DMFM, Emery P, Bathon JM, Keystone E, et al. Radiographic changes in rheumatoid arthritis patients attaining different disease activity states with methotrexate monotherapy and infliximab plus methotrexate: the impacts of remission and tumour necrosis factor blockade. Ann Rheum Dis 2009;68:823-7.

[45] Gaujoux-Viala C, Rincheval N, Dougados M, Combe B, Fautrel B. Optimal methotrexate dose is associated with better clinical outcomes than non-optimal dose in daily practice: results from the ESPOIR early arthritis cohort. Ann Rheum Dis 2017;76:2054-60.

[46] Furst DE, Koehnke R, Burmeister LF, Kohler J, Cargill I. Increasing methotrexate effect with increasing dose in the treatment of resistant rheumatoid arthritis. J Rheumatol 1989;16:313-20.

[47] Schiff MH, Sadowski P. Oral to subcutaneous methotrexate dose-conversion strategy in the treatment of rheumatoid arthritis. Rheumatol Int 2017;37:213-8.

[48] Visser K, Katchamart W, Loza E, Martinez-Lopez JA, Salliot C, Trudeau J, et al. Multinational evidence-based recommendations for the use of methotrexate in rheumatic disorders with a focus on rheumatoid arthritis: integrating systematic literature research and expert opinion of a broad international panel of rheumatologists in the 3E Initiative. Ann Rheum Dis 2009;68:1086-93.

[49] Verschueren P, De Cock D, Corluy L, Joos R, Langenaken C, Taelman V, et al. Methotrexate in combination with other DMARDs is not superior to methotrexate alone for remission induction with moderate-to-high-dose glucocorticoid bridging in early rheumatoid arthritis after 16 weeks of treatment: the CareRA trial. Ann Rheum Dis 2015;74:27-34.

[50] ter Wee MM, den Uyl D, Boers M, Kerstens P, Nurmohamed M, van Schaardenburg D, et al. Intensive combination treatment regimens, including prednisolone, are effective in treating patients with early rheumatoid arthritis regardless of additional etanercept: 1-year 
results of the COBRA-light open-label, randomised, non-inferiority trial. Ann Rheum Dis 2015;74:1233-40.

[51] De Jong PH, Hazes JM, Han HK, Huisman M, Van Zeben D, Van Der Lubbe PA, et al. Randomised comparison of initial triple DMARD therapy with methotrexate monotherapy in combination with low-dose glucocorticoid bridging therapy; 1-year data of the tREACH trial. Ann Rheum Dis 2014;73:1331-9.

[52] Takeuchi T, Yamanaka H, Ishiguro N, Miyasaka N, Mukai M, Matsubara T, et al. Adalimumab, a human anti-TNF monoclonal antibody, outcome study for the prevention of joint damage in Japanese patients with early rheumatoid arthritis: The HOPEFUL 1 study. Ann Rheum Dis 2014;73:536-43.

[53] Scott IC, Ibrahim F, Simpson G, Kowalczyk A, White-Alao B, Hassell A, et al. A randomised trial evaluating anakinra in early active rheumatoid arthritis. Clin Exp Rheumatol 2016;34:88-93.

[54] Atsumi T, Yamamoto K, Takeuchi T, Yamanaka H, Ishiguro N, Tanaka Y, et al. The first double-blind, randomised, parallel-group certolizumab pegol study in methotrexate-naive early rheumatoid arthritis patients with poor prognostic factors, C-OPERA, shows inhibition of radiographic progression. Ann Rheum Dis 2016;75:75-83.

[55] Bijlsma JWJ, Welsing PMJ, Woodworth TG, Middelink LM, Pethö-Schramm A, Bernasconi C, et al. Early rheumatoid arthritis treated with tocilizumab, methotrexate, or their combination (U-Act-Early): a multicentre, randomised, double-blind, double-dummy, strategy trial. Lancet Lond Engl 2016;388:343-55.

[56] Nam JL, Villeneuve E, Hensor EM, Conaghan PG, Keen HI, Buch MH, et al. Remission induction comparing infliximab and high-dose intravenous steroid, followed by treat-totarget: a double-blind, randomised, controlled trial in new-onset, treatment-naive, rheumatoid arthritis (the IDEA study). Ann Rheum Dis 2014;73:75-85. 
[57] Rempenault C, Combe B, Barnetche T, Gaujoux-Viala C, Lukas C, Morel J, et al. Metabolic and cardiovascular benefits of hydroxychloroquine in patients with rheumatoid arthritis: a systematic review and meta-analysis. Ann Rheum Dis 2018;77:98-103.

[58] Verschueren P, De Cock D, Corluy L, Joos R, Langenaken C, Taelman V, et al. Effectiveness of methotrexate with step-down glucocorticoid remission induction (COBRA Slim) versus other intensive treatment strategies for early rheumatoid arthritis in a treat-totarget approach: 1-year results of CareRA, a randomised pragmatic open-label superiority trial. Ann Rheum Dis 2017;76:511-20.

[59] Safy M, Jacobs J, IJff ND, Bijlsma J, van Laar JM, de Hair M, et al. Long-term outcome is better when a methotrexate-based treatment strategy is combined with $10 \mathrm{mg}$ prednisone daily: follow-up after the second Computer-Assisted Management in Early Rheumatoid Arthritis trial. Ann Rheum Dis 2017;76:1432-5.

[60] Roubille C, Rincheval N, Dougados M, Flipo R-M, Daurès J-P, Combe B. Seven-year tolerability profile of glucocorticoids use in early rheumatoid arthritis: data from the ESPOIR cohort. Ann Rheum Dis 2017;76:1797-802.

[61] Ruyssen-Witrand A, Constantin A. Controversies in rheumatoid arthritis glucocorticoid therapy. Jt Bone Spine Rev Rhum 2018;85:417-22.

[62] Listing J, Kekow J, Manger B, Burmester G-R, Pattloch D, Zink A, et al. Mortality in rheumatoid arthritis: the impact of disease activity, treatment with glucocorticoids, TNF $\alpha$ inhibitors and rituximab. Ann Rheum Dis 2015;74:415-21.

[63] Roubille C, Richer V, Starnino T, McCourt C, McFarlane A, Fleming P, et al. The effects of tumour necrosis factor inhibitors, methotrexate, non-steroidal anti-inflammatory drugs and corticosteroids on cardiovascular events in rheumatoid arthritis, psoriasis and psoriatic arthritis: a systematic review and meta-analysis. Ann Rheum Dis 2015;74:480-9. 
[64] de Jong PH, Hazes JM, Han HK, Huisman M, van Zeben D, van der Lubbe PA, et al. Randomised comparison of initial triple DMARD therapy with methotrexate monotherapy in combination with low-dose glucocorticoid bridging therapy; 1-year data of the tREACH trial. Ann Rheum Dis 2014;73:1331-9.

[65] Nam JL, Villeneuve E, Hensor EM, Conaghan PG, Keen HI, Buch MH, et al. Remission induction comparing infliximab and high-dose intravenous steroid, followed by treat-totarget: a double-blind, randomised, controlled trial in new-onset, treatment-naive, rheumatoid arthritis (the IDEA study). Ann Rheum Dis 2014;73:75-85.

[66] Fautrel B, Granger B, Combe B, Saraux A, Guillemin F, Le Loet X. Matrix to predict rapid radiographic progression of early rheumatoid arthritis patients from the community treated with methotrexate or leflunomide: Results from the ESPOIR cohort. Arthritis Res Ther 2012;14:R249.

[67] Vastesaeger N, Xu S, Aletaha D, St Clair EW, Smolen JS. A pilot risk model for the prediction of rapid radiographic progression in rheumatoid arthritis. Rheumatol Oxf Engl 2009;48:1114-21.

[68] Klarenbeek NB, Güler-Yüksel M, van der Kooij SM, Han KH, Ronday HK, Kerstens PJSM, et al. The impact of four dynamic, goal-steered treatment strategies on the 5-year outcomes of rheumatoid arthritis patients in the BeSt study. Ann Rheum Dis 2011;70:1039-46.

[69] Kiely P, Walsh D, Williams R, Young A, Early Rheumatoid Arthritis N. Outcome in rheumatoid arthritis patients with continued conventional therapy for moderate disease activity--the early RA network (ERAN). Rheumatology 2011;50:926-31.

[70] Fleischmann R, Mysler E, Hall S, Kivitz AJ, Moots RJ, Luo Z, et al. Efficacy and safety of tofacitinib monotherapy, tofacitinib with methotrexate, and adalimumab with methotrexate in patients with rheumatoid arthritis (ORAL Strategy): a phase 3b/4, double-blind, head-tohead, randomised controlled trial. Lancet Lond Engl 2017;390:457-68. 
[71] Schiff M, Weinblatt ME, Valente R, van der Heijde D, Citera G, Elegbe A, et al. Head-tohead comparison of subcutaneous abatacept versus adalimumab for rheumatoid arthritis: two-year efficacy and safety findings from AMPLE trial. Ann Rheum Dis 2014;73:86-94.

[72] Taylor PC, Keystone EC, van der Heijde D, Weinblatt ME, Del Carmen Morales L, Reyes Gonzaga J, et al. Baricitinib versus Placebo or Adalimumab in Rheumatoid Arthritis. N Engl J Med 2017;376:652-62.

[73] Nam JL, Takase-Minegishi K, Ramiro S, Chatzidionysiou K, Smolen JS, van der Heijde D, et al. Efficacy of biological disease-modifying antirheumatic drugs: a systematic literature review informing the 2016 update of the EULAR recommendations for the management of rheumatoid arthritis. Ann Rheum Dis 2017;76:1113-36.

[74] Singh JA, Hossain A, Tanjong Ghogomu E, Mudano AS, Tugwell P, Wells GA. Biologic or tofacitinib monotherapy for rheumatoid arthritis in people with traditional disease-modifying anti-rheumatic drug (DMARD) failure: a Cochrane Systematic Review and network metaanalysis (NMA). Cochrane Database Syst Rev 2016;11:CD012437.

[75] de La Forest Divonne M, Gottenberg JE, Salliot C. Safety of biologic DMARDs in RA patients in real life: A systematic literature review and meta-analyses of biologic registers. Jt Bone Spine Rev Rhum 2017;84:133-40.

[76] Cohen SB, Tanaka Y, Mariette X, Curtis JR, Lee EB, Nash P, et al. Long-term safety of tofacitinib for the treatment of rheumatoid arthritis up to 8.5 years: integrated analysis of data from the global clinical trials. Ann Rheum Dis 2017;76:1253-62.

[77] Curtis JR, Xie F, Yun H, Bernatsky S, Winthrop KL. Real-world comparative risks of herpes virus infections in tofacitinib and biologic-treated patients with rheumatoid arthritis. Ann Rheum Dis 2016;75:1843-7.

[78] Hauser SL, Waubant E, Arnold DL, Vollmer T, Antel J, Fox RJ, et al. B-cell depletion with rituximab in relapsing-remitting multiple sclerosis. N Engl J Med 2008;358:676-88. 
[79] Coleman M, Lammers PE, Ciceri F, Jacobs IA. Role of Rituximab and Rituximab Biosimilars in Diffuse Large B-Cell Lymphoma. Clin Lymphoma Myeloma Leuk 2016;16:175-81.

[80] Khoury SJ, Rochon J, Ding L, Byron M, Ryker K, Tosta P, et al. ACCLAIM: A randomized trial of abatacept (CTLA4-Ig) for relapsing-remitting multiple sclerosis. Mult Scler Houndmills Basingstoke Engl 2017;23:686-95.

[81] Scott DL, Ibrahim F, Farewell V, O’Keeffe AG, Walker D, Kelly C, et al. Tumour necrosis factor inhibitors versus combination intensive therapy with conventional disease modifying anti-rheumatic drugs in established rheumatoid arthritis: TACIT non-inferiority randomised controlled trial. BMJ 2015;350:h1046.

[82] Fleischmann R, Tongbram V, van Vollenhoven R, Tang DH, Chung J, Collier D, et al. Systematic review and network meta-analysis of the efficacy and safety of tumour necrosis factor inhibitor-methotrexate combination therapy versus triple therapy in rheumatoid arthritis. RMD Open 2017;3:e000371.

[83] Buckley F, Finckh A, Huizinga TWJ, Dejonckheere F, Jansen JP. Comparative Efficacy of Novel DMARDs as Monotherapy and in Combination with Methotrexate in Rheumatoid Arthritis Patients with Inadequate Response to Conventional DMARDs: A Network MetaAnalysis. J Manag Care Spec Pharm 2015;21:409-23.

[84] Dougados M, Kissel K, Sheeran T, Tak PP, Conaghan PG, Mola EM, et al. Adding tocilizumab or switching to tocilizumab monotherapy in methotrexate inadequate responders: 24-week symptomatic and structural results of a 2-year randomised controlled strategy trial in rheumatoid arthritis (ACT-RAY). Ann Rheum Dis 2013;72:43-50.

[85] Burmester GR, Rigby WF, van Vollenhoven RF, Kay J, Rubbert-Roth A, Blanco R, et al. Tocilizumab combination therapy or monotherapy or methotrexate monotherapy in methotrexate-naive patients with early rheumatoid arthritis: 2-year clinical and radiographic 
results from the randomised, placebo-controlled FUNCTION trial. Ann Rheum Dis 2017;76:1279-84.

[86] Kaneko Y, Atsumi T, Tanaka Y, Inoo M, Kobayashi-Haraoka H, Amano K, et al. Comparison of adding tocilizumab to methotrexate with switching to tocilizumab in patients with rheumatoid arthritis with inadequate response to methotrexate: 52-week results from a prospective, randomised, controlled study (SURPRISE study). Ann Rheum Dis 2016;75:1917-23.

[87] Fleischmann R, Schiff M, van der Heijde D, Ramos-Remus C, Spindler A, Stanislav M, et al. Baricitinib, Methotrexate, or Combination in Patients With Rheumatoid Arthritis and No or Limited Prior Disease-Modifying Antirheumatic Drug Treatment. Arthritis Rheumatol Hoboken NJ 2017;69:506-17.

[88] Burmester G-R, Kivitz AJ, Kupper H, Arulmani U, Florentinus S, Goss SL, et al. Efficacy and safety of ascending methotrexate dose in combination with adalimumab: the randomised CONCERTO trial. Ann Rheum Dis 2015;74:1037-44.

[89] Kaeley GS, Evangelisto AM, Nishio MJ, Goss SL, Liu S, Kalabic J, et al. Methotrexate Dosage Reduction Upon Adalimumab Initiation: Clinical and Ultrasonographic Outcomes from the Randomized Noninferiority MUSICA Trial. J Rheumatol 2016;43:1480-9.

[90] Finckh A, Dehler S, Gabay C, SCQM doctors. The effectiveness of leflunomide as a cotherapy of tumour necrosis factor inhibitors in rheumatoid arthritis: a population-based study. Ann Rheum Dis 2009;68:33-9.

[91] De Stefano R, Frati E, Nargi F, Baldi C, Menza L, Hammoud M, et al. Comparison of combination therapies in the treatment of rheumatoid arthritis: leflunomide-anti-TNF-alpha versus methotrexate-anti-TNF-alpha. Clin Rheumatol 2010;29:517-24. 
[92] Soliman MM, Hyrich KL, Lunt M, Watson KD, Symmons DPM, Ashcroft DM, et al. Effectiveness of rituximab in patients with rheumatoid arthritis: observational study from the British Society for Rheumatology Biologics Register. J Rheumatol 2012;39:240-6.

[93] Schaeverbeke T, Truchetet M-E, Kostine M, Barnetche T, Bannwarth B, Richez C. Immunogenicity of biologic agents in rheumatoid arthritis patients: lessons for clinical practice. Rheumatol Oxf Engl 2016;55:210-20.

[94] Gabay C, Riek M, Hetland ML, Hauge E-M, Pavelka K, Tomšič M, et al. Effectiveness of tocilizumab with and without synthetic disease-modifying antirheumatic drugs in rheumatoid arthritis: results from a European collaborative study. Ann Rheum Dis 2016;75:1336-42.

[95] Lauper K, Nordström D, Pavelka K. Retention of tocilizumab as monotherapy versus TNF inhibitors with conventional synthetic DMARDs in rheumatoid arthritis patients with inadequate response to TNF inhibitors: a study from the TOCERRA collaboration, Ann Rheum Dis; 2017;76(suppl 2):850.

[96] Gabay C, Emery P, van Vollenhoven R, Dikranian A, Alten R, Pavelka K, et al. Tocilizumab monotherapy versus adalimumab monotherapy for treatment of rheumatoid arthritis (ADACTA): a randomised, double-blind, controlled phase 4 trial. Lancet Lond Engl 2013;381:1541-50.

[97] Burmester GR, Lin Y, Patel R, van Adelsberg J, Mangan EK, Graham NMH, et al. Efficacy and safety of sarilumab monotherapy versus adalimumab monotherapy for the treatment of patients with active rheumatoid arthritis (MONARCH): a randomised, double-blind, parallelgroup phase III trial. Ann Rheum Dis 2017;76:840-7.

[98] van Riel PLCM, Taggart AJ, Sany J, Gaubitz M, Nab HW, Pedersen R, et al. Efficacy and safety of combination etanercept and methotrexate versus etanercept alone in patients with rheumatoid arthritis with an inadequate response to methotrexate: the ADORE study. Ann Rheum Dis 2006;65:1478-83. 
[99] Lethaby A, Lopez-Olivo MA, Maxwell L, Burls A, Tugwell P, Wells GA. Etanercept for the treatment of rheumatoid arthritis. Cochrane Database Syst Rev 2013:CD004525.

[100] Truchetet M-E, Poursac N, Barnetche T, Shipley E, Gottenberg J-E, Bannwarth B, et al. Abatacept monotherapy compared with abatacept plus disease-modifying anti-rheumatic drugs in rheumatoid arthritis patients: data from the ORA registry. Arthritis Res Ther $2016 ; 18: 72$

[101] Nüßlein HG, Alten R, Galeazzi M, Lorenz H-M, Nurmohamed MT, Bensen WG, et al. Prognostic factors for abatacept retention in patients who received at least one prior biologic agent: an interim analysis from the observational, prospective ACTION study. BMC Musculoskelet Disord 2015;16:176.

[102] Schoels M, Aletaha D, Smolen JS, Wong JB. Comparative effectiveness and safety of biological treatment options after tumour necrosis factor $\alpha$ inhibitor failure in rheumatoid arthritis: systematic review and indirect pairwise meta-analysis. Ann Rheum Dis 2012;71:1303-8.

[103] Manders SHM, Kievit W, Adang E, Brus HL, Moens HJB, Hartkamp A, et al. Costeffectiveness of abatacept, rituximab, and TNFi treatment after previous failure with TNFi treatment in rheumatoid arthritis: a pragmatic multi-centre randomised trial. Arthritis Res Ther 2015;17:134.

[104] Gottenberg J-E, Brocq O, Perdriger A, Lassoued S, Berthelot J-M, Wendling D, et al. NonTNF-Targeted Biologic vs a Second Anti-TNF Drug to Treat Rheumatoid Arthritis in Patients With Insufficient Response to a First Anti-TNF Drug: A Randomized Clinical Trial. JAMA 2016;316:1172-80.

[105] Du Pan SM, Scherer A, Gabay C, Finckh A. Differential drug retention between anti-TNF agents and alternative biological agents after inadequate response to an anti-TNF agent in rheumatoid arthritis patients. Ann Rheum Dis 2012;71:997-9. 
[106] Smolen JS, Burmester G-R, Combe B, Curtis JR, Hall S, Haraoui B, et al. Head-to-head comparison of certolizumab pegol versus adalimumab in rheumatoid arthritis: 2-year efficacy and safety results from the randomised EXXELERATE study. Lancet Lond Engl 2016;388:2763-74.

[107] Curtis JR, Bykerk VP, Aassi M, Schiff M. Adherence and Persistence with Methotrexate in Rheumatoid Arthritis: A Systematic Review. J Rheumatol 2016;43:1997-2009.

[108] de Thurah A, Nørgaard M, Harder I, Stengaard-Pedersen K. Compliance with methotrexate treatment in patients with rheumatoid arthritis: influence of patients' beliefs about the medicine. A prospective cohort study. Rheumatol Int 2010;30:1441-8.

[109] Lillegraven S, Prince FHM, Shadick NA, Bykerk VP, Lu B, Frits ML, et al. Remission and radiographic outcome in rheumatoid arthritis: application of the 2011 ACR/EULAR remission criteria in an observational cohort. Ann Rheum Dis 2012;71:681-6.

[110] Sigaux J, Bailly F, Hajage D, Mariette X, Morel J, Gandjbakhch F, et al. Sustainability of TNF-blocker tapering in rheumatoid arthritis over 3 years: long-term follow-up of the STRASS (Spacing of TNF-blocker injections in Rheumatoid ArthritiS Study) randomised controlled trial. RMD Open 2017;3:e000474.

[111] Bouman CA, van Herwaarden N, van den Hoogen FH, Fransen J, van Vollenhoven RF, Bijlsma JW, et al. Long-term outcomes after disease activity-guided dose reduction of TNF inhibition in rheumatoid arthritis: 3-year data of the DRESS study - a randomised controlled pragmatic non-inferiority strategy trial. Ann Rheum Dis 2017;76:1716-22.

[112] Takeuchi T, Matsubara T, Ohta S, Mukai M, Amano K, Tohma S, et al. Biologic-free remission of established rheumatoid arthritis after discontinuation of abatacept: a prospective, multicentre, observational study in Japan. Rheumatol Oxf Engl 2015;54:68391. 
[113] Mariette X, Rouanet S, Sibilia J, Combe B, Le Loët X, Tebib J, et al. Evaluation of low-dose rituximab for the retreatment of patients with active rheumatoid arthritis: a non-inferiority randomised controlled trial. Ann Rheum Dis 2014;73:1508-14.

[114] Takeuchi T, Genovese MC, Haraoui B, Li Z, Xie L, Klar R. Abstract 1821: Dose Reduction of Baricitinib in Patients with Rheumatoid Arthritis Achieving Sustained Disease Control: Results of a Prospective Stud. Arthritis Rheumatol 2017;Abstract Supplement:2594-6.

[115] Smolen JS, Emery P, Ferraccioli GF, Samborski W, Berenbaum F, Davies OR, et al. Certolizumab pegol in rheumatoid arthritis patients with low to moderate activity: the CERTAIN double-blind, randomised, placebo-controlled trial. Ann Rheum Dis 2015;74:843-50.

[116] Schett G, Emery P, Tanaka Y, Burmester G, Pisetsky DS, Naredo E, et al. Tapering biologic and conventional DMARD therapy in rheumatoid arthritis: current evidence and future directions. Ann Rheum Dis 2016;75:1428-37.

[117] Fautrel B, Den Broeder AA. De-intensifying treatment in established rheumatoid arthritis (RA): Why, how, when and in whom can DMARDs be tapered? Best Pract Res Clin Rheumatol 2015;29:550-65.

[118] Kuijper TM, Luime JJ, de Jong PHP, Gerards AH, van Zeben D, Tchetverikov I, et al. Tapering conventional synthetic DMARDs in patients with early arthritis in sustained remission: 2-year follow-up of the tREACH trial. Ann Rheum Dis 2016;75:2119-23.

[119] Haschka J, Englbrecht M, Hueber AJ, Manger B, Kleyer A, Reiser M, et al. Relapse rates in patients with rheumatoid arthritis in stable remission tapering or stopping antirheumatic therapy: interim results from the prospective randomised controlled RETRO study. Ann Rheum Dis 2016;75:45-51. 
[120] Radner H, Yoshida K, Frits M, Iannaccone C, Shadick NA, Weinblatt M, et al. The impact of multimorbidity status on treatment response in rheumatoid arthritis patients initiating disease-modifying anti-rheumatic drugs. Rheumatol Oxf Engl 2015;54:2076-84.

[121] Peters MJL, van Halm VP, Voskuyl AE, Smulders YM, Boers M, Lems WF, et al. Does rheumatoid arthritis equal diabetes mellitus as an independent risk factor for cardiovascular disease? A prospective study. Arthritis Rheum 2009;61:1571-9.

[122] Roubille C, Richer V, Starnino T, McCourt C, McFarlane A, Fleming P, et al. The effects of tumour necrosis factor inhibitors, methotrexate, non-steroidal anti-inflammatory drugs and corticosteroids on cardiovascular events in rheumatoid arthritis, psoriasis and psoriatic arthritis: a systematic review and meta-analysis. Ann Rheum Dis 2015;74:480-9.

[123] Agca R, Heslinga SC, Rollefstad S, Heslinga M, McInnes IB, Peters MJL, et al. EULAR recommendations for cardiovascular disease risk management in patients with rheumatoid arthritis and other forms of inflammatory joint disorders: 2015/2016 update. Ann Rheum Dis 2017;76:17-28.

[124] Daïen CI, Tubery A, Cailar G du, Mura T, Roubille F, Morel J, et al. Application of the 2015/2016 EULAR recommendations for cardiovascular risk in daily practice: data from an observational study. Ann Rheum Dis 2018;77:625-6.

[125] Baillet A, Gossec L, Carmona L, Wit M de, van Eijk-Hustings Y, Bertheussen H, et al. Points to consider for reporting, screening for and preventing selected comorbidities in chronic inflammatory rheumatic diseases in daily practice: a EULAR initiative. Ann Rheum Dis 2016;75:965-73.

[126] van Assen S, Agmon-Levin N, Elkayam O, Cervera R, Doran MF, Dougados M, et al. EULAR recommendations for vaccination in adult patients with autoimmune inflammatory rheumatic diseases. Ann Rheum Dis 2011;70:414-22. 
[127] Mikuls TR, Payne JB, Yu F, Thiele GM, Reynolds RJ, Cannon GW, et al. Periodontitis and Porphyromonas gingivalis in patients with rheumatoid arthritis. Arthritis Rheumatol Hoboken NJ 2014;66:1090-100.

[128] Chou Y-Y, Lai K-L, Chen D-Y, Lin C-H, Chen H-H. Rheumatoid Arthritis Risk Associated with Periodontitis Exposure: A Nationwide, Population-Based Cohort Study. PloS One 2015;10:e0139693.

[129] Ortiz P, Bissada NF, Palomo L, Han YW, Al-Zahrani MS, Panneerselvam A, et al. Periodontal therapy reduces the severity of active rheumatoid arthritis in patients treated with or without tumor necrosis factor inhibitors. J Periodontol 2009;80:535-40.

[130] Daïen CI, Tubery A, Beurai-Weber M, Cailar G du, Picot M-C, Roubille F, et al. Relevance and feasibility of a systematic screening of multimorbidities in patients with chronic inflammatory rheumatic diseases. Joint Bone Spine 2018. doi:10.1016/j.jbspin.2018.03.016.

[131] Dougados M, Soubrier M, Perrodeau E, Gossec L, Fayet F, Gilson M, et al. Impact of a nurse-led programme on comorbidity management and impact of a patient self-assessment of disease activity on the management of rheumatoid arthritis: results of a prospective, multicentre, randomised, controlled trial (COMEDRA). Ann Rheum Dis 2015;74:1725-33.

[132] Gossec L, Baillet A, Dadoun S, Daien C, Berenbaum F, Dernis E, et al. Collection and management of selected comorbidities and their risk factors in chronic inflammatory rheumatic diseases in daily practice in France. Jt Bone Spine Rev Rhum 2016;83:501-9.

[133] Sisti LG, Dajko M, Campanella P, Shkurti E, Ricciardi W, de Waure C. The effect of multifactorial lifestyle interventions on cardiovascular risk factors: a systematic review and meta-analysis of trials conducted in the general population and high risk groups. Prev Med 2018;109:82-97. 
[134] Thomsen T, Aadahl M, Beyer N, Hetland ML, Løppenthin K, Midtgaard J, et al. The efficacy of motivational counselling and SMS reminders on daily sitting time in patients with rheumatoid arthritis: a randomised controlled trial. Ann Rheum Dis 2017;76:1603-6.

[135] Joseph RM, Movahedi M, Dixon WG, Symmons DPM. Smoking-Related Mortality in Patients With Early Rheumatoid Arthritis: A Retrospective Cohort Study Using the Clinical Practice Research Datalink. Arthritis Care Res 2016;68:1598-606.

[136] Soderlin MK, Petersson IF, Bergman S, Svensson B, group B study. Smoking at onset of rheumatoid arthritis (RA) and its effect on disease activity and functional status: experiences from BARFOT, a long-term observational study on early RA. Scand J Rheumatol 2011;40:249-55.

[137] Vittecoq O, Richard L, Banse C, Lequerré T. The impact of smoking on rheumatoid arthritis outcomes. Jt Bone Spine Rev Rhum 2018;85:135-8.

[138] Guasch-Ferré M, Hu FB, Martínez-González MA, Fitó M, Bulló M, Estruch R, et al. Olive oil intake and risk of cardiovascular disease and mortality in the PREDIMED Study. BMC Med 2014;12:78.

[139] McKellar G, Morrison E, McEntegart A, Hampson R, Tierney A, Mackle G, et al. A pilot study of a Mediterranean-type diet intervention in female patients with rheumatoid arthritis living in areas of social deprivation in Glasgow. Ann Rheum Dis 2007;66:1239-43.

[140] Gioxari A, Kaliora AC, Marantidou F, Panagiotakos DP. Intake of $\omega-3$ polyunsaturated fatty acids in patients with rheumatoid arthritis: A systematic review and meta-analysis. Nutr Burbank Los Angel Cty Calif 2018;45:114-124.e4.

[141] Potter MDE, Brienesse SC, Walker MM, Boyle A, Talley NJ. Effect of the gluten-free diet on cardiovascular risk factors in patients with coeliac disease: A systematic review. J Gastroenterol Hepatol 2018;33:781-91. 
[142] Lebwohl B, Cao Y, Zong G, Hu FB, Green PHR, Neugut AI, et al. Long term gluten consumption in adults without celiac disease and risk of coronary heart disease: prospective cohort study. BMJ 2017;357:j1892. 


\section{FIGURE LEGENDS}

Figure 1. Categories of currently available disease-modifying anti-rheumatic drugs Biologics include abatacept, adalimumab, certolizumab pegol, etanercept, golimumab, infliximab, rituximab, sarilumab, tocilizumab, and others.

Figure 2. Setting treatment goals and organizing the management program (adapted from Smolen et al. [2])

RA, rheumatoid arthritis; TJC, tender joint count; SJC, swollen joint count; aVAS, visual analog scale for patient assessment of disease activity; CRP, C-reactive protein; DAS28, 28joint disease activity score; SDAI, Simplified Disease Activity Index; CDAI, Clinical Disease Activity Index; HAQ, Health Assessment Questionnaire

Figure 3. Strategy for the pharmacological treatment of rheumatoid arthritis (RA) RFs, rheumatoid factors; ACPA, anti-citrullinated peptide antibodies; csDMARD, conventional synthetic disease-modifying anti-rheumatic drug; bDMARD, biologic diseasemodifying anti-rheumatic drug; tsDMARD, targeted synthetic disease-modifying antirheumatic drug; IL-6R, interleukin-6 receptor; JAKi, JAK inhibitor; MTX, methotrexate; LEF, leflunomide; SSZ, sulfasalazine; recs: recommendations; TNF, tumor necrosis factor

Figure 4. Global management of patients with rheumatoid arthritis (RA)

Diphtheria-tetanus-polio immunization every 10 years; influenza immunization once a year; pneumococcal immunization every 5 years; same schedule for the other immunizations as in the general population 
DISEASE-MODIFYING ANTI-RHEUMATIC DRUGS

CONVENTIONAL SYNTHETIC:

csDMARDs (methotrexate, leflunomide, sulfasalazine, hydroxychloroquine)
TARGETED THERAPIES

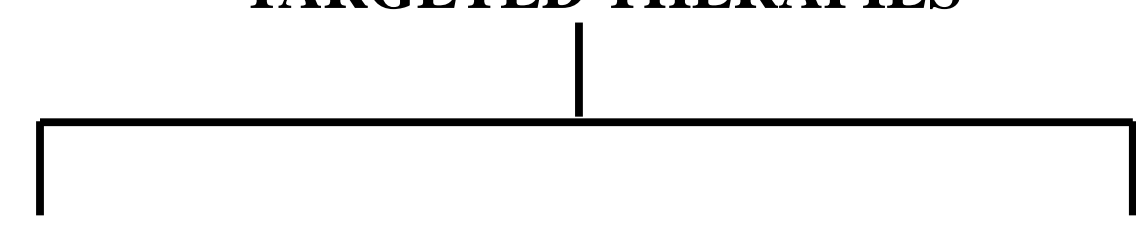

BIOLOGICS: bDMARDs

- originators: boDMARDs

- biosimilars: bsDMARDs 


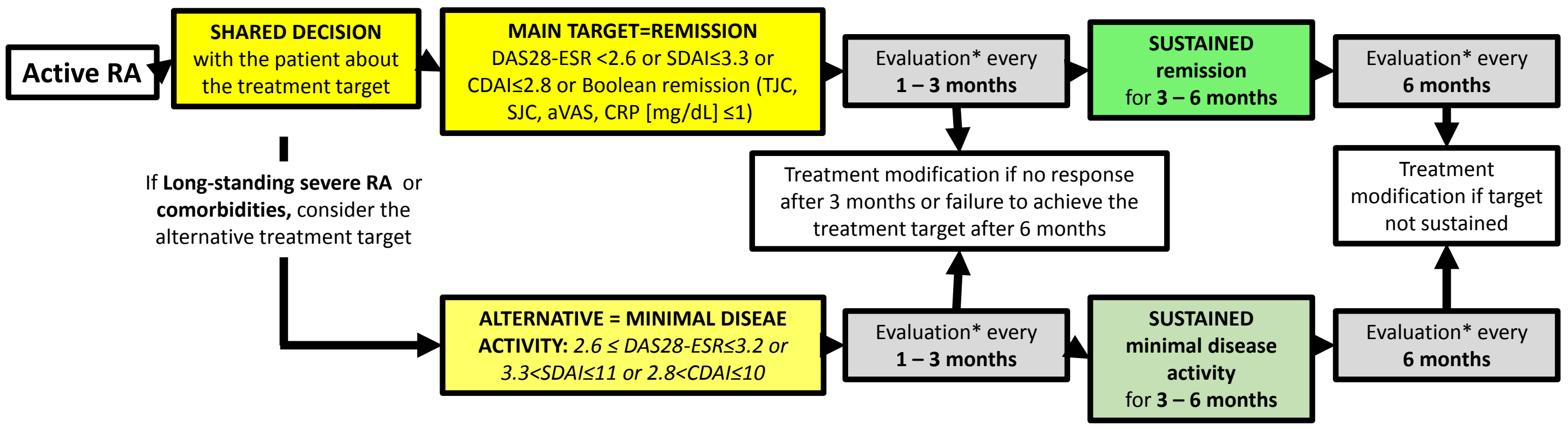

* Evaluation of efficacy based on whether the treatment target is achieved. Annual evaluation of the functional impact of RA using the HAQ is recommended. Follow-up radiographs are recommended, notably in patients with residual clinical activity and when the disease-modifying anti-rheumatic drug regimen is changed. 
METHOTREXATE (MTX): optimal dosage (15-30 $\mathrm{mg} /$ week) within 4-8 weeks

$\pm$

Glucocorticoid: low cumulative dose, 6 months $\max$

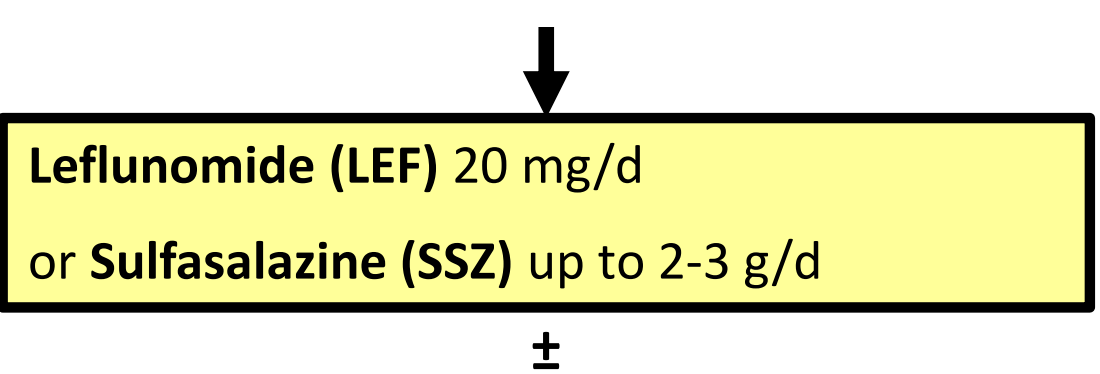

Glucocorticoid: low cumulative dose, 6 months max
Significant improvement after 3 months and treatment target achieved after 6 months?

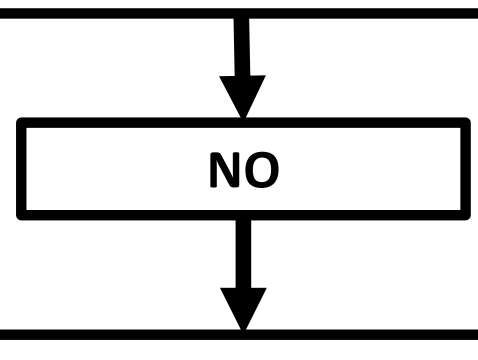

Erosions, RFs/ACPA, moderate-to-high activity, failure of $\geq 2$ csDMARDs

\section{ADD A TARGETED THERAPY}

bDMARD (TNF $\alpha$ antagonist, IL-6R antagonist, abatacept; if contraindication, rituximab)

or tsDMARD (JAKi)

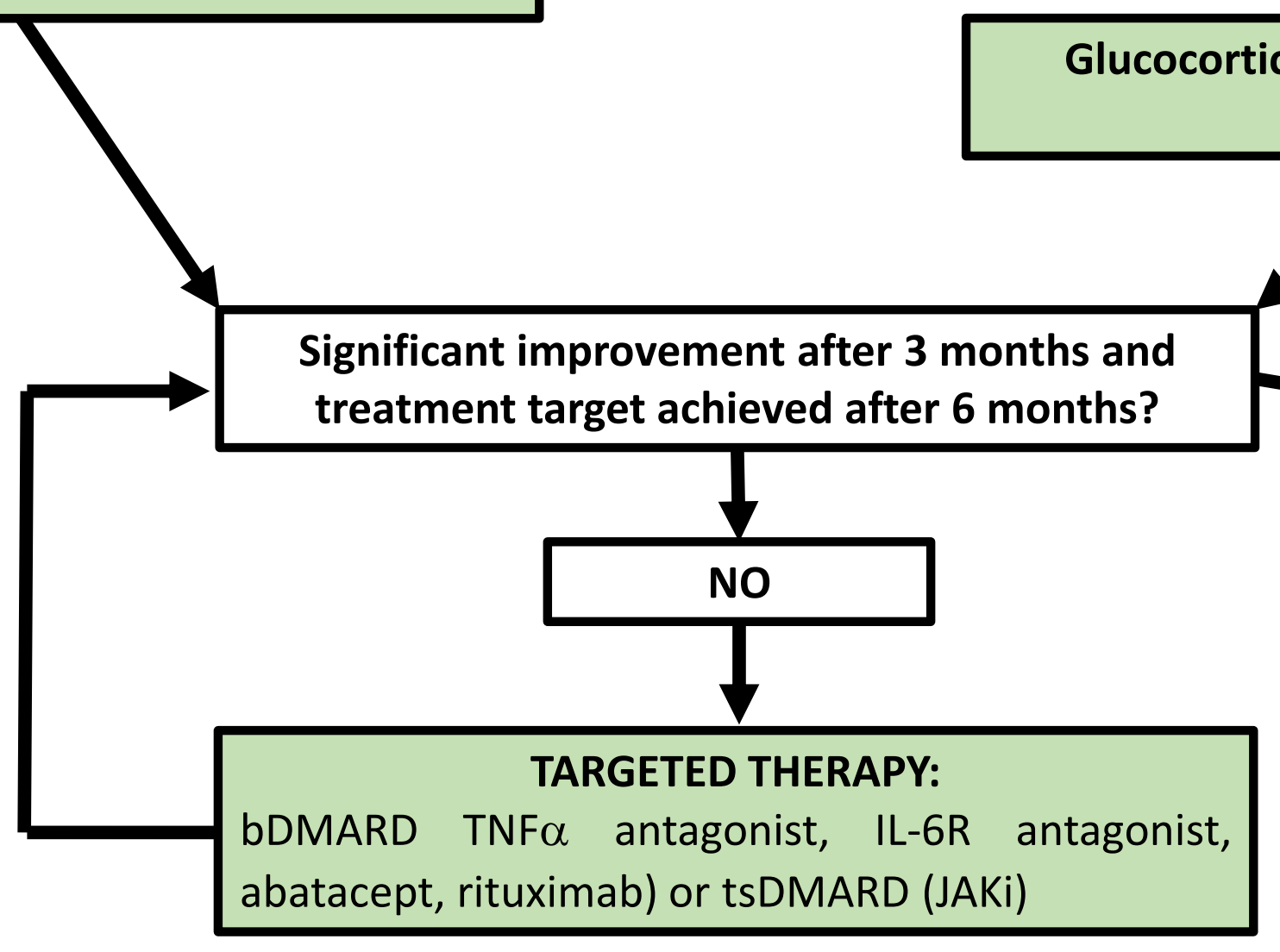
abatacept, rituximab) or tsDMARD (JAKi)
SWITCH TO OR ADD ANOTHER CSDMARD:

LEF, SSZ, MTX, alone or in combination

$\pm$

ES: continue same treatment then, if sustained remission without glucocorticoids, discuss csDMARD deescalation
YES: continue same treatment then, if sustained remission without glucocorticoids, discuss b/tsDMARD deescalation

Manage the remission (recs 12-13) 
Global and multidisciplinary management

RHUMATOLOGIST, PRIMARY-CARE PHYSICIAN, physiotherapist/occupational therapist, specialized nurse, cardiologist, dietician, dentist, psychologist, social worker

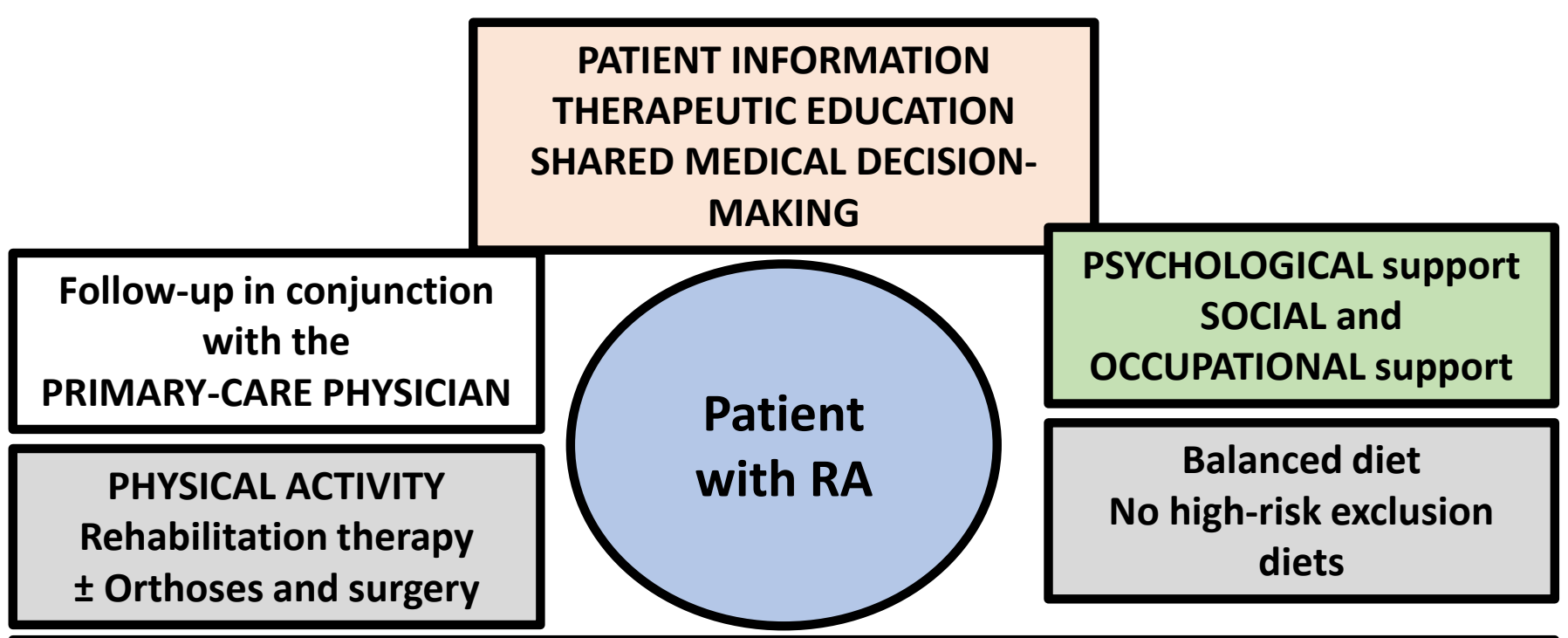

REGULAR EVALUATION \pm MANAGEMENT OF

cardiovascular risk factors: serum lipid assays (outside flares), blood pressure, smoking, obesity

immunizations (influenza, DTP, pneumococcus) and cancer screening tests oral health

the risk of osteoporosis

- lung and gastrointestinal tract involvement

depression 


\section{Table 1. Definitions of terms}

\begin{tabular}{|c|c|}
\hline Terms & Definitions \\
\hline $\begin{array}{l}\text { Factors of adverse prognostic } \\
\text { significance }\end{array}$ & $\begin{array}{l}\text { - } \text { Early bone erosions } \\
\text { - } \quad \begin{array}{l}\text { Elevated laboratory markers of inflammation (ESR } \\
\text { and CRP) }\end{array} \\
\text { - } \text { High swollen joint count } \\
\text { - } \begin{array}{l}\text { Presence of rheumatoid factors and ACPAs, } \\
\text { particularly in high titers ( } \geq 3 \mathrm{~N})\end{array} \\
\text { - } \text { Moderate-to-high disease activity despite } \\
\text { csDMARD therapy* } \\
\text { - } \text { Failure of } \geq 2 \text { csDMARDs* }\end{array}$ \\
\hline Sustained remission & $\begin{array}{l}\text { Remission (according to composite criteria including a } \\
\text { joint evaluation) sustained for at least } 6 \text { months }\end{array}$ \\
\hline
\end{tabular}


Table 2. 2018 recommendations of the French Society for Rheumatology (Société Française de Rhumatologie, SFR) about the management of rheumatoid arthritis (RA)

\begin{tabular}{|c|c|c|c|c|}
\hline General principles and recommendations & $\begin{array}{l}\text { Level of } \\
\text { evidence }\end{array}$ & Grade & $\begin{array}{l}\text { Agreement, } \\
\text { Task force } \\
\text { Mean (SD) }\end{array}$ & $\begin{array}{l}\text { Agreement, } \\
\text { Review } \\
\text { panel } \\
\text { Mean (SD) }\end{array}$ \\
\hline \multicolumn{5}{|l|}{ GENERAL PRINCIPLES } \\
\hline $\begin{array}{l}\text { A. The optimal management of patients with RA } \\
\text { requires a dialogue between the rheumatologist } \\
\text { and patient to ensure that the patient receives the } \\
\text { information and education needed to share in his } \\
\text { or her management decisions. }\end{array}$ & NA & NA & $10(0)$ & $9.3(1.2)$ \\
\hline $\begin{array}{l}\text { B. The rheumatologist is the specialist who } \\
\text { should be in charge of managing patients with } \\
\text { RA. The primary-care physician plays a crucial } \\
\text { role in detecting RA and in providing follow-up } \\
\text { in conjunction with the rheumatologist. }\end{array}$ & NA & NA & $9.7(0.8)$ & $9.8(0.6)$ \\
\hline $\begin{array}{l}\text { C. Patients with RA should be offered a global } \\
\text { management program including drug treatments, } \\
\text { therapeutic patient education and, as appropriate, } \\
\text { comorbidity management, psychological } \\
\text { support, assistance with social and occupational } \\
\text { issues, functional rehabilitation, and/or surgery. }\end{array}$ & NA & NA & $9.7(0.6)$ & $9.2(1.3)$ \\
\hline $\begin{array}{l}\text { D. The cost of RA and of its consequences and } \\
\text { treatments, for both the individual and society, } \\
\text { should be considered when making treatment } \\
\text { decisions. }\end{array}$ & NA & NA & $9.3(1.0)$ & $7.6(2.9)$ \\
\hline \multicolumn{5}{|l|}{ RECOMMENDATIONS } \\
\hline \multicolumn{5}{|l|}{ Diagnosis } \\
\hline $\begin{array}{l}\text { 1. A diagnosis of RA should be } \\
\text { - considered in patients with specific clinical } \\
\text { findings such as joint swelling (clinical } \\
\text { arthritis), morning stiffness lasting longer } \\
\text { than } 30 \text { minutes, and a positive hand or } \\
\text { forefoot squeeze test } \\
\text { - then confirmed as promptly as possible } \\
\text { (ideally within } 6 \text { weeks) by a physical } \\
\text { examination performed by a rheumatologist, } \\
\text { laboratory tests (erythrocyte sedimentation } \\
\text { rate [ESR], C-reactive protein [CRP], anti- } \\
\text { citrullinated protein antibodies [ACPA], and } \\
\text { rheumatoid factors [RFs]), and imaging } \\
\text { studies (radiographs with or without }\end{array}$ & $\mathrm{IIb}$ & $\mathrm{B}$ & $9.7(0.5)$ & $9.4(1.0)$ \\
\hline
\end{tabular}


ultrasonography), after ruling out the differential diagnoses.

2. As soon as RA is diagnosed, disease- Ia modifying treatment must be initiated.

3. The treatment target is achieving and Ia maintaining a remission or, at least, minimal disease activity. A clinical remission is defined as the absence of signs and symptoms of significant inflammatory activity.

4. Disease activity should be measured using Ia validated composite criteria, including joint indices.

5. Follow-up should be provided by a rheumatologist at closely spaced intervals (every 1 to 3 months) as long as the disease is active. Treatment adjustments are in order in patients who fail to improve within 3 months or to achieve their treatment target within 6 months.

A $\quad 9.9(0.5) \quad 9.4(1.0)$

A $\quad 9.8(0.4) \quad 9.3(1.1)$

B $\quad 9.6(0.7) \quad 9.1(1.5)$

B $\quad 9.8(0.4) \quad 9.3(1.2)$

First-line treatment

6. . Methotrexate is the first-line DMARD in patients with active RA, starting at a dosage of at least $10 \mathrm{mg} /$ week then reaching the optimal dosage within no more than 4-8 weeks.

7. In DMARD-naive patients who have contraindications or early intolerance to methotrexate, leflunomide and sulfasalazine are good alternatives.

8. While awaiting the effects of csDMARD therapy, oral or parenteral glucocorticoid therapy can be considered, in a low cumulative dosage, if possible for no longer than 6 months. The glucocorticoid dose should be tapered to nothing as promptly as possible.

\section{Second and subsequent treatment lines}

9. In patients with an inadequate response or intolerance to methotrexate, the treatment must be optimized.

- In patients with adverse prognostic factors,

$\begin{array}{llll}\text { Ia } & \text { A } & 9.3(1.0) & 8.5(2.0)\end{array}$
add-on bDMARD or tsDMARD therapy can be considered, using a TNF $\square$ antagonist, abatacept, an IL-6 pathway antagonist, a JAK inhibitor, or, under specific circumstances, rituximab. ${ }^{\#}$

$9.2(0.9)$

$8.4(2.1)$ 


\begin{tabular}{|c|c|c|c|c|}
\hline $\begin{array}{l}\text { - In patients without adverse prognostic } \\
\text { factors, a switch to another csDMARD } \\
\text { (leflunomide, sulfasalazine) or the } \\
\text { combination of several csDMARDs can be } \\
\text { considered; if this strategy fails or is } \\
\text { contraindicated, targeted therapy (with a } \\
\text { bDMARD or tsDMARD) should be } \\
\text { considered. }\end{array}$ & ${ }^{8} \mathrm{~V}$ & ${ }^{\S} \mathrm{D}$ & & \\
\hline $\begin{array}{l}\text { 10. All targeted therapies (bDMARDs }{ }^{*} \text { or } \\
\text { tsDMARDs }{ }^{\#} \text { ) are best used in combination with } \\
\text { methotrexate.. }\end{array}$ & $\begin{array}{c}{ }^{*} \mathrm{Ia} \\
{ }^{\#} \mathrm{Ib}\end{array}$ & A & $9.5(0.7)$ & $8.9(2.0)$ \\
\hline $\begin{array}{l}\text { 11. Patients who fail a first targeted therapy } \\
\text { (bDMARD or tsDMARD) should be switched to } \\
\text { another targeted therapy. In the event of primary } \\
\text { failure, a switch to a targeted therapy that has a } \\
\text { different mechanism of action may deserve } \\
\text { preference. }\end{array}$ & ${ }^{{ }^{*} \mathrm{Ia}}$ & $\mathrm{A}$ & $9.6(0.6)$ & $9.0(1.5)$ \\
\hline \multicolumn{5}{|l|}{ Managing disease remission } \\
\hline $\begin{array}{l}\text { 12. In patients who have a sustained remission } \\
\text { without glucocorticoid therapy, a decrease in the } \\
\text { targeted therapy dosage must be considered. }\end{array}$ & IIb & B & $9.1(1.4)$ & $8.7(1.9)$ \\
\hline $\begin{array}{l}\text { 13. In patients who have a sustained remission } \\
\text { without targeted therapy or glucocorticoid } \\
\text { therapy, cSDMARD de-escalation can be } \\
\text { considered. }\end{array}$ & IV & $\mathrm{C}$ & $9.0(1.4)$ & $8.7(2.1)$ \\
\hline \multicolumn{5}{|l|}{ Global patient management } \\
\hline $\begin{array}{l}\text { 14. Treatment selection and adjustment should } \\
\text { factor in a number of considerations in addition } \\
\text { to measured disease activity, such as structural } \\
\text { disease progression, comorbidities, tolerance of } \\
\text { the drugs, treatment adherence, and the patient's } \\
\text { wishes. }\end{array}$ & $\begin{array}{c}{ }^{*} \mathrm{Ia} \\
{ }^{\#} \mathrm{Ib}\end{array}$ & $\mathrm{C}$ & $9.8(0.4)$ & $9.6(0.8)$ \\
\hline $\begin{array}{l}\text { 15. Screening for and periodic evaluations of } \\
\text { comorbidities and their risk factors, as well as } \\
\text { periodic evaluations of their management, } \\
\text { should be provided. The management program } \\
\text { should include lifestyle advice (e.g., about } \\
\text { regular physical activity, smoking cessation, and } \\
\text { a healthy diet) and immunization updates. }\end{array}$ & ${ }^{\$} \mathrm{IIb}$ & $\mathrm{C}$ & $9.4(0.9)$ & $9.1(1.7)$ \\
\hline
\end{tabular}

Recommendations are graded based on the level of underlying evidence; A is the highest grade.

NA, not applicable

${ }^{\mathrm{a}}$ Agreement scored on a 0-10 scale where 10 indicates complete agreement 